\title{
SEPARATION OF POWERS AND THE TAX LEVEL IN THE U.S. STATES
}

\author{
Leandro De Magalhães \\ Lucas Ferrero
}

Discussion Paper 14 / 620

Revised 8 December 2014

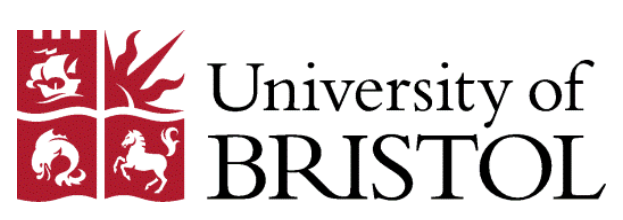

Department of Economics

University of Bristol

8 Woodland Road

Bristol BS8 1TN

United Kingdom 


\title{
Separation of Powers and the Tax Level in the U.S. States*
}

\author{
Leandro De Magalhães ${ }^{\dagger}$ \\ Lucas Ferrero \\ University of Bristol \\ Universidad Nacional del Nordeste
}

November 9, 2014

\begin{abstract}
We estimate a non-linear and discontinuous relationship between the tax level and the degree of alignment between the legislature and the governor, measured as the number of seats in the legislature that belong to the governor's party. In the states with the line-item veto, there is a jump in the tax level at the point where the government switches from divided to unified. With a regression discontinuity design, we show that this jump can be interpreted as a causal effect. We propose a simple model to account for this non-linear relationship. The sequential nature of the budget bargaining game, i.e. the legislature proposes and the governor cuts with the line-item veto, implies that the tax level is determined by the overlap between the supporters of the governor and the supporters of the legislative majority. Changes in the size of the overlap determine the tax level.
\end{abstract}

JEL: H00, H11, H20, H30, H71.

${ }^{*}$ We would like to thank Guido Tabellini and Antonio Merlo for their extensive help during the early drafts of this paper. We would also like to thank seminar participants in Bocconi, Bristol, at the Political Science department at Washington University at St. Louis, at the EPSA meeting in Dublin 2011, and at the Public Choice meeting in Miami in 2012.

† leandro.demagalhaes@bristol.ac.uk

† lferrero@eco.unne.edu.ar 
Spatial models with veto players have been extensively used to study the role of the separation of powers on policy. In this literature, the testable predictions focus mostly on how the policy change takes place: whether it is deliberate or automatic; large or small; or the speed of change (Tsebelis (2002)). In particular, the spatial model does not provide us with a clear prediction of whether the separation of powers and different types of veto power should increase or decrease the size of government. If a player's bliss point implies a high tax level, then the veto allows this player to increase the tax level; if the player's bliss point implies a low tax level, taxes decrease. The literature that has studied the line-item veto (Holtz-Eakin (1988), Carter and Schap (1990), and Dearden and Husted (1993)), model the line-item veto as a stronger form of veto power than the block veto. The prediction of these papers is that the line-item veto allows the governor to achieve an outcome closer to her bliss point than she would be able to with the block veto. No clear prediction regarding the tax level arises, because the bliss point is unobserved by the researcher.

Papers such as Persson et al. (2000) make very clear predictions on how the institutional separation of powers affects the tax level. The model assumes, as we do in this paper, that each agent tries to implement the level of transfers that maximizes the utility of their own constituency. Persson et al. (2000) rely on a particular form of separation of powers: one agent proposes the tax level and then another agent proposes the allocation. They also rely on a clear separation between constituencies: each agent represents a different group of voters with no overlap. The prediction of their model is categorical: taxes should be lower with this form of separation of powers than in a model with no separation. The drawback of this model is that it lacks the rich and variable predictions allowed by the spatial models on how the ideological distance between veto players affects policy.

The main contribution of this paper is to bring these two strands of the literature together. In order to do this, we focus on the institutional setup of the American states and on the political conflict over the amount of transfers (pork-barrel) each district receives. ${ }^{1}$ Our focus on the pork-barrel component of the budget allows us to separate ideology from the tax level. Ideology and party identity play an important role in defining the notion of ideological location in the model, but we make the simplifying assumption that ideological preferences are orthogonal to the preferred level of transfers and to the tax level. ${ }^{2}$

\footnotetext{
${ }^{1}$ In this sense, our model builds on the literature on pork-barrel politics Lindbeck and Weibull (1987), Cox and McCubbins (1986), Myerson (1993), Dixti and Londgren (1995), Dixti and Londgren (1998).

${ }^{2}$ The intuition for this assumption is that ideology may determine how the money is spent, but every district prefers more transfers to themselves to less for a given level of taxation. And every district would rather not pay taxes if the that district is to receive zero transfers.
} 
The distance between the two players in our model, the legislative and the executive branches, will not be defined in the usual ideological space. The only ideological restriction is that the districts that voted for the $D$ party will be located to the left of districts that voted for the $R$ party. The distance between the two players, or their degree of alignment, is defined by the number of districts (voters) that support both the sitting governor and the majority in the legislature. The larger the number of this type of district, the higher the degree of alignment between the governor and the legislature. The model predicts that the tax level varies with this distance. Note that this setup allows for a high degree of alignment between a governor and a legislative majority from different parties as long as a high proportion of districts have split their vote.

The sequential nature of the budget process in the American states (the legislature is the deciding body on both the tax level and the allocation of resources, and the governor is only allowed to veto the budget), generates testable predictions on the tax level that do not require differential political preferences among the veto players regarding the tax level. ${ }^{3}$ The model predicts a non-linear relationship between the tax level and the degree of alignment between the governor and the state legislature. The predicted shape of the relationship differs between states where the governor has the block veto or the line-item veto. In particular, the model predicts an increase in the tax level as the government moves from divided to unified, but only in the state with the line-item veto. In the states with the block veto, the tax level is predicted to be continuous at this cutoff.

The line-item veto is a key feature of our model and it is widespread throughout the U.S. states; it allows the governor to veto particular items and words, or to trim values within the budget. In a minority of states, the governor has block veto power. The block veto is a similar veto power to that of the U.S. President: the executive branch cannot selectively veto pieces of legislation, but instead must veto all of it. In our model, the line-item veto allows the governor to prevent the legislative majority from being the full residual claimant of a tax increase, which implies a lower tax level in equilibrium. This is a similar mechanism to the one suggested in Persson et al. (2000). A contribution of the paper is to show that this mechanism works with the institutional setup found in most U.S. states, and that it is not limited to the stylized institutional setting of Persson et al. (2000). Moreover, the notion of distance we introduce in this context allows for the tax level to vary with the degree of alignment between the governor and the legislature.

Finally, this paper makes an empirical contribution to two strands of the literature. One strand has looked at the effect of the line-item veto on the tax level and the other has

\footnotetext{
${ }^{3} \mathrm{~A}$ series of papers find little or no evidence that the party identity of the governor affects the tax level: Besley and Case (2003), Reed (2006), Leigh (2008), Warren et al. (2013). Ferreira and Gyourko (2009) and Gerber and Hopkins (2011) find no evidence that the partisan identity of U.S. mayors affects the tax level.
} 
focused on the effects of divided government. On the line-item veto, Abrams and Dougan (1986), Holtz-Eakin (1988), Alm and Evers (1991), Dearden and Husted (1993), Besley and Case (2003), and de Figueiredo Jr. (2003) have found little evidence for it being effective in reducing the size of government. ${ }^{4}$ In contrast, our regression discontinuity design finds that a divided government in a state with the line-item veto effectively reduces the tax level. ${ }^{5}$

The empirical literature that has looked on how unified versus divided government affects the tax level has treated these variables as categorical, i.e. either divided or unified (see Poterba (1994), Alt and Lowry (1994), Bohn and Inman (1996), and Besley and Case (2003)). Our contribution is to allow the degree of alignment to vary with the number of seats in the legislature that belong to the governor's party and to use a regression discontinuity design to infer the causal effect of a divided government on the tax level. For the empirical counterpart of our model, we define the degree of alignment as the minimum between the two legislative chambers, as in order to approve the budget a simple majority is required in both the House and the Senate. We call this variable Governor's strength. As Governor's strength crosses the $50 \%$ mark the government becomes unified, below the $50 \%$ mark the government is divided. ${ }^{6}$ The evidence we find suggests that the relationship between Governor's strength and the tax level is non-linear and discontinuous at the $50 \%$ mark for states with the line-item veto, whereas the relationship is found to be continuous for states with the block veto.

The structure of this paper is as follows. In Section 1, we present the model. In Section 2 , we estimate with a partially linear model the non-linear and discontinuous function between Governor's strength and the tax level (Section 2.2); and show that the jump at the $50 \%$ mark (the point at which the government switches from divided to unified) is valid as a regression discontinuity design (Section 2.3). In Section 3, we conclude.

\footnotetext{
${ }^{4}$ So far this literature has attempted to deal with endogeneity by using fixed effect estimators.

${ }^{5}$ McCarty and Poole (1995) look at the role of the block veto power yielded by the U.S. President. Alemán and Schwartz (2006) have looked at the effect of the line-item veto in Latin American and Tsebelis and Rizova (2007) in former communist countries.

${ }^{6}$ For the main intuition of the model, only one chamber is necessary. Empirically, the alternative definition would be to classify a government as unified as long as one chamber is aligned with the governor. In Section A.6 on the on-line appendix we show that there is no jump in the tax level as we move from divided to unified government with this alternative definition. Our results suggest that both chambers must be aligned for there to be a discernible effect on the tax level at the cutoff.
} 


\section{Model}

\section{$1.1 \quad$ Set up}

We present a model based on the formal features of the budget process in the US states. The budgetary outcome is determined in a sequential bargaining game between two players. First, the legislature approves a budget bill. ${ }^{7}$ Second, the governor decides whether to exercise veto power. ${ }^{8}$ There are two possible types of veto power that we define in detail below: line-item veto and block veto.

There are two parties: $D$ and $R$. We assume that parties are organizations that provide party members with a commitment device for logrolling within the legislature. As in Grossman and Helpman (2008), the legislative majority party maximizes the sum of the utilities of every district in the majority's group, denoted by the set $L$. Likewise, the winning governor maximizes the sum of utilities of all districts that supported her, denoted by the set $G .^{9}$

Consider a representative state with a continuum of districts on the interval $[0,1]$. A generic district $x$ in the state is populated by a mass one of identical agents with preferences over budget outcomes given by the utility function:

$$
v_{(x)}=\widetilde{y}-\tau+V\left(f_{(x)}\right)
$$

where $f_{(x)}$ is a district specific program; $V(\cdot)$ is a continuous, twice differentiable, increasing, strictly concave function, implying decreasing marginal net benefits of spending programs. ${ }^{10}$ The lump sum tax $\tau$ is the same for each district. Each district has a net endowment $\widetilde{y}=y+H(\bar{g})-\tau^{g}$, where $\bar{g}$ is general per capita spending. $H(\bar{g})-\tau^{g}>0$ is the net per capita benefit and $\tau^{g}=\bar{g}$ is the level of taxation that funds these general items. We assume $\tau^{g}=\bar{g}$ to be exogenously given, and that $H(\bar{g})-\tau^{g}>V^{-1}\left(\frac{1}{2}\right) \cdot{ }^{11}$

\footnotetext{
${ }^{7}$ In most states the governor or a budget agency produces the first draft. We skip this step as once the budget reaches the legislature it can be amended at will. See the National Association of State Budget Offices (NASBO) publication 'Budget Process in the States' at http://www.nasbo.org.

${ }^{8}$ In most states, the legislature may override the veto with a qualified majority. For simplicity, we ignore the veto override. This is consistent with the empirical strategy of focusing on slim majorities. In the online appendix, Section A.2, we extend the model and allow the override to deactivate the veto power once the legislative majority reaches the required threshold.

${ }^{9}$ In contrast to Grossman and Helpman (2008), our model assigns an important role to parties in the determination of this overlap and on how the ideological space is defined; and our model describes the budget as a sequential bargaining game. Grossman and Helpman (2008) focus, instead, on how the legislative branch is willing to delegate discretionary power to the executive.

${ }^{10} \mathrm{We}$ build our model on the lines of Persson et al. (2000), with targetable transfers to single-member districts. The model's results regarding the behavior of the tax level around the cutoff do not rely on transfers being targetable to specific groups. In the on-line Appendix we show that the results are robust to a specification with two state-wide general items, each of which is preferred by one of the two parties.

${ }^{11}$ The intuition for this assumption is that the net benefit of the general type of spending $\bar{g}$, which we
} 
Spending $\bar{g}$ captures two aspects of the budget that we do not model explicitly: budget inertia and the costs of a government shut-down when the block veto is used. In the data, the tax level measured as a percentage of state GDP does not change much over the time period we study. ${ }^{12}$ This is mostly due to the substantial amount of the revenues being pre-committed to particular expenditures. ${ }^{13}$ Within our model, the levels of $f_{(x)}$ are an addition to this fixed level of the state-wide general expenditures. ${ }^{14}$

The budget must be balanced both at the proposal stage and after the veto:

$$
f=\int_{x=0}^{1} f_{(x)} d x \leq \tau
$$

Formally, the legislative majority chooses the amount of transfers for each district $f_{(x)}$, and overall taxation $\tau$, by solving the following maximization problem:

$$
\max _{f_{(x)}, \tau} \int_{x \in L} v_{(x)} d x, \text { subject to } \int_{i} f_{(x)} d x \leq \tau \text {. }
$$

Under the line-item veto, the governor may only cut or trim the transfers $f_{(x)}$ chosen by the legislative majority and therefore solves the following maximization problem: ${ }^{15}$

$$
\max _{f_{(x)}, \tau} \int_{x \in G} v_{(x)} d x, \text { subject to } \int_{x} f_{(x)} d x \leq \tau \text { and } f_{(x)} \leq f_{(x) L} \forall x .
$$

where $f_{(x) L}$ denotes the level of transfers to a given district $x$ approved by the legislative majority.

Under the block veto, the governor chooses between the budget proposed by the legislative majority and a government shut-down, i.e., $\tau=f=\tau^{g}=\bar{g}=0 .{ }^{16}$

have in mind to be schools, police, hospitals, road maintenance and so on, are high enough relative to the benefit from transfers $f_{(x)}$.

${ }^{12}$ See Table 1 in Section 2.1

${ }^{13}$ Specifically, incremental budgeting is the traditional budgeting method whereby the budget is prepared by taking the current period's budget or actual performance as a base, with incremental amounts then being added for the new budget period.

${ }^{14} \mathrm{We}$ model the budget with one line item for each district. This is for simplicity. Districts may also be interpreted as lobbies, unions, churches, or other pressure groups. Transfers $f$ can more generally be interpreted as budget lines that cross over some districts or groups. The careful vetoing of some of these line has the effect of cutting or trimming the transfers to a specific group of these districts. The interpretation of these groups as geographic districts is necessary for mapping the model to the data in Section 2.

${ }^{15}$ We assume the governor cannot trim the general expenditure $\bar{g}$. This assumption is for simplicity. Allowing the governor to trim $g$ would complicate the results without qualitatively changing them.

${ }^{16}$ In practice, during a shutdown, government employees stay at home and all government-provided services stop, except for those within essential areas. See NCSL document 'Procedures When the Appropriations Act is Not Passed by the Beginning of the Fiscal Year': http://ncsl.org. For a detailed description of federal government shutdowns see Meyers (1997). Two of the states with the block veto (North Carolina and New Hampshire) allow for continuing temporary resolutions. Three others (Nevada, Virginia, and Washington) have no specific procedures to deal with this eventuality, which means that 
We take the electoral outcome as given and study the implied tax level for all possible resulting political configurations. The political configuration can be represented on a $[0,1]$ line as follows. ${ }^{17}$ There is a continuum of districts on the interval $[0,1]$. Assume that the governor belongs to party $D .{ }^{18}$ We stack from left to right all districts that have voted for the governor from party $D$, this interval is the set $G$ and its size is denoted by $s_{G} \geq 0.5$. Let $s_{G}$ also denote the rightmost district that has voted for party $D$, so that the interval can be represented as $\left[0, s_{G}\right]$. Likewise $L$ denotes the set of districts that support the legislative majority and $s_{L} \geq 0.5$ denotes its size. If the legislative majority belongs to party $D, s_{L}$ is the size of the interval $\left[0, s_{L}\right]$, where $s_{L} \geq 0.5$ is also the rightmost district that voted for party $D$. Whereas, if the legislative majority belongs to party $R, s_{L}$ is the size of the interval $\left[1-s_{L}, 1\right]$, where $1-s_{L} \leq 0.5$ is the leftmost district that voted for party $R$. If there is a unified government the overlap between $G$ and $L$ is the interval $\left[0, \min \left\{s_{G}, s_{L}\right\}\right]$ and its size is given by $\min \left\{s_{G}, s_{L}\right\}$. If there is a divided government the overlap between $G$ and $L$ is the interval $\left[1-s_{L}, s_{G}\right]$ and its size is given by $s_{G}-\left(1-s_{L}\right){ }^{19}$

Summarizing, the timing of the game is as follows: 1) the exogenous election outcome determines the government configuration, which is fully observed by all players; 2) the legislature approves the budget bill and its implied tax level by simple majority; 3) the governor may veto the budget or cut programs according to the type of veto power available, line-item or block veto.

\subsection{Results}

Lemma 1.1 In the states with the line-item veto, only the districts that are both part of the legislative majority and part of the governor's support receive positive transfers $f_{(x)}>0$ in equilibrium. We call these districts the overlapping districts.

We focus on the intuition, and leave the formal proof to the online appendix, Section A.1. At the last stage, the governor vetoes to zero any proposed transfers $f_{(x) L}$ to districts not in her support. Any positive transfers to these districts entail a higher tax

a government shut-down is possible. In the remaining states (Indiana, Iowa, Maine, and Vermont), a government shut-down is determined by state law in the case of a stalemate in the budget process.

${ }^{17}$ In an election stage, the representation of the ideological space in one dimension implies that there can only be one type of vote splitting in equilibrium (see Alesina and Rosenthal (1996)). This is in line with our representation of branches' interest overlap bellow.

${ }^{18}$ This is without loss of generality as the labels can be switched around.

${ }^{19}$ As an example assume that $s_{G}=0.6$, i.e. all districts from 0 to 0.6 support the $D$ governor. We compare two legislative majorities one from party $D$ and one from party $R$, both have the same size: $s_{L}=0.55$. Under a unified government all districts from 0 to 0.55 support the legislative majority from party $D$ and the overlap is given by these 0.55 districts. Under a divided government $s_{L}=0.55$ implies that districts in the interval $[0.45,1]$ support the legislative majority composed of party $R$ districts; the overlap is the interval $[0.45,0.6]$ and the size of the overlap is $s_{G}-\left(1-s_{L}\right)=0.6-(1-0.55)=0.15$. 
level with no marginal benefit to the districts in her support. The governor cuts to zero all $f_{(x) L}$ when $x \notin G$; and trims part of $f_{(x) L}$ for $x \in G$ if its level are considered excessive.

At the first stage of the bargaining, the legislative majority will not assign positive transfers $f_{(x) L}>0$ to districts not in the legislative majority. These would only entail a cost in the form of additional taxes.

Lemma 1.2 For $\frac{1}{2}<s_{G}<1$, the size of the overlapping set of districts displays a discontinuity as the government configuration switches from a divided to a unified government.

Again we focus on the intuition here and leave the proof to the online appendix, Section A.1. Let us keep the assumption that the governor belongs to party $D$. Under a divided government party $R$ holds the majority in the legislature. The size of the overlap is given by the fraction of the districts in $G$ that support the legislative majority of party $R$. Formally, if the governor is from one party and the legislative majority is from another party, then the size of the overlap is given by $s_{G}-\left(1-s_{L}\right)>0$. Under a unified government the size of the overlap is given by $\min \left\{s_{G}, s_{L}\right\}$.

Within each configuration, the degree of alignment is a smooth continuous function in the share of districts in the legislative majority. However, this is not the case when the majority party switches in the legislature. Under a unified government, as $s_{L}$ approaches the cutoff (from the right), the smallest possible overlap is given by $\min \left\{s_{G}, s_{L}\right\}=\frac{1}{2}$. But under a divided government the overlap at the cutoff is arbitrarily close to $s_{G}-\frac{1}{2}$. The jump is given by $\Delta=1-s_{G}$. The discontinuity is present unless the governor has $100 \%$ of support. Only in this limit case, does a switch from divided to unified government implies no change in the number of districts in the overlapping interval.

Given Lemma 1.1 and 1.2, we may now determine the equilibrium tax level.

Proposition 1 If the governor has the line-item veto, for any $\frac{1}{2} \leq s_{G}<1$, taxes are: (a) discontinuous at $s_{L}=0.5$; under a unified government (b) strictly increasing in the interval $s_{L} \in\left[\frac{1}{2}, s_{G}\right)$, (c) strictly decreasing in the interval $s_{L} \in\left[s_{G}, 1\right]$; under a divided government (d) strictly decreasing in the interval $1-s_{L} \in\left(1-s_{G}, \frac{1}{2}\right)$; (e) and ambiguous in the interval $1-s_{L} \in\left[0,1-s_{G}\right]$.

For the proof, see the online appendix, Section A.1. To give the intuition, we start at the last stage with the governor's decision. According to Lemma 1.1, the governor will assign zero transfers to districts outside $G$. The Governor's preferred level of transfers for each district in her support is given by $f_{(x)}=V^{-1}\left(s_{G}\right)=f\left(s_{G}\right)$ for all $x \in G$. With line-item veto power, the governor trims down legislative proposals with $f_{(x) L}>f\left(s_{G}\right)$. 
The legislative majority assigns zero resources to districts outside $L$. The desired (maximum) expenditure proposed by $L$ is given by $f_{(x)}=V^{-1}\left(s_{L}\right)=f\left(s_{L}\right)$ for all $x \in L$. Since we assume the veto to be costless to exercise, the legislative majority can be considered to solve the maximization problem (5) without accounting for the governor's further behavior. This is a weakly dominant strategy for the legislative majority.

Note that the size of the overlap does not determine the optimal level of transfers for each district. The optimal level for both the governor an for the legislative majority is only determined by $s_{G}$ and $s_{L}$ respectively. For this reason the legislative majority can solve an unconstrained maximization and assign $f_{(x) L}=f\left(s_{L}\right)$ to every district in $L$ and let the governor cut to zero any transfers to those districts not in the overlap (and trim those in the overlap if necessary, i.e. if $\left.s_{G}>s_{L}\right) .{ }^{20}$ Note that $\frac{d f\left(s_{B}\right)}{d s_{B}}<0$ for $B=G, L$, implies that if $s_{B}<s_{B^{\prime}}$ then the desired levels of transfers for districts in each support bear $f\left(s_{B^{\prime}}\right)<f\left(s_{B}\right)$. This means that the branch with the larger constituency internalizes more the aggregate costs of taxation and will prefer a lower level of district specific transfer.

Part $(a)$. The reason the tax level decreases as we move from a unified to a divided government has already been discussed in Lemma 1.2: the size of the overlapping set decreases discontinuously. Note that on both sides of the cutoff $s_{L} \leq s_{G}$. This means that the governor determines the level of transfers for each district. For a fixed $s_{G}$ the amount each district in the overlap receives on both sides of the cutoff is the same. As the size of the overlap changes discontinuously, so does the tax level.

Part $(b)$. This refers to the interval $\left[0.5, s_{G}\right)$. The overlapping set has size $s_{L}$, since $s_{L}<s_{G}$ and the government is unified. Note that since $s_{L}<s_{G}$, the governor internalizes more of the cost of taxation than the legislative majority. This implies that the governor determines the level of transfers for those districts in the overlapping set. For a fixed $s_{G}$, as $s_{L}$ increases so does the number of districts receiving positive transfers, which pushes taxes up.

Part $(c)$. This refers to the interval $\left[s_{G}, 1\right]$. For $s_{L} \geq s_{G}$ the overlapping set is now fixed at $s_{G}$. Since $s_{G}<s_{L}$, the legislative majority internalizes more of the cost of taxation and therefore sets a level of transfers that is bellow the governor's desired level. The governor has no need to trim positive levels of transfers assigned to the overlapping set. As $s_{L}$ increases, the marginal cost of taxation for the legislative majority increases. This means that they set lower transfers $f\left(s_{L}\right)$. For a given size of the overlapping set, $s_{G}$, the set of beneficiaries is fixed, and the overall tax level falls with $f\left(s_{L}\right)$ as $s_{L}$ increases.

Part $(d)$. This refers to the interval $\left(1-s_{G}, 0.5\right)$. The government is divided, the

\footnotetext{
${ }^{20}$ The quasi-linear form of the objective function (additively separable and linear in taxation), implies that marginal cost of taxation and the marginal benefit of $f_{(x)}$ do not interact, as is shown in the proof in the online appendix Section A.1.
} 
legislative majority is given by the interval $\left[1-s_{L}, 1\right]$ and the overlap by the interval $\left[1-s_{L}, s_{G}\right]$. The larger support is given by $s_{G}>s_{L}$, which implies that the governor chooses the level of transfers in equilibrium. As $s_{L}$ decreases, the size of the overlap decreases, which implies that the number of districts receiving positive transfers also decreases, but the amount each district receives is fixed and determined by the governor. This implies that the tax level is decreasing in the interval $\left[1-s_{G}, 0.5\right]$.

Part $(e)$. This refers to the interval $\left[0,1-s_{G}\right]$. The government is divided as in part $(d)$. The difference is that $s_{L}>s_{G}$, which means that the legislative majority determines the level of transfers. The veto power stops having bite as a trimming mechanism for the level of transfers. Two forces are at play. The first is the same as in part $(d)$ : as $s_{L}$ decreases, the size of the overlap decreases, which implies that the number of districts receiving positive transfers also decreases. This force pushes the tax level down. The second force goes in the opposite direction: as $s_{L}$ decreases, the legislative majority internalizes the cost of taxation less. This implies that the legislative majority will choose a higher level of transfer for each district in $L$ as $s_{L}$ decreases. This force pushes the tax level up. If the $V(\cdot)$ function is concave enough, the second force dominates.

Proposition 2 If the governor has block veto, for any $\frac{1}{2} \leq s_{G}<1$ the legislative majority determines both the set of beneficiaries and the level of transfers, and taxes are continuous at $s_{L}=\frac{1}{2}$.

For the proof see the online appendix, Section A.1. With the block veto, all the action is driven by $s_{L}$. To see this, first note that it is too costly for the governor to exercise a block veto. Consider the extreme case in which marginal taxation and transfers carries no benefit to $G$ : a divided configuration with $s_{G}=1 / 2$ and $s_{L} \simeq 0.5$. The tax level $\tau$ is only a cost to the governor. No one in $G$ receives positive transfers, but they have to pay $\tau$. If all transfers were to be trimmed down to zero, the governor's welfare would increase by $\frac{1}{2} f\left(\frac{1}{2}\right)$ as taxation would decrease by $f\left(\frac{1}{2}\right)$ for all districts in $L$. However, the block veto shuts down the whole budget, which implies the loss of the net benefits $H(\bar{g})-\tau^{g}$ per capita and per district. The aggregate loss is then $\frac{1}{2}\left[H(\bar{g})-\tau^{g}\right]$. The net benefit is negative as $H(\bar{g})-\tau^{g}>V^{-1}\left(\frac{1}{2}\right)$, by assumption.

The overall level of taxation is then determined by

$$
\tau^{B V}=\int_{x \in L} f_{(x) L} d x=s_{L} f\left(s_{L}\right),
$$

with $s_{L} \in[0.5,1]$ continuous for any party configuration. Thus the size of the majority pins down both the set of beneficiaries and the level of transfers. Two opposite forces 
are at play as we add one member to the majority: the size of the majority increases, which pushes the tax level up; but any higher taxes have to be shared equally, and this force pushes the tax level down. If $V($.$) is close to linear, the first effect dominates and$ the function relating the size of the majority and the tax level takes a ' $\mathrm{V}$ ' shape on the $[0,1]$ line, with the inflection point at $s_{L}=0.5$. If $V($.$) is concave enough it takes an$ 'inverted-V' shape. 


\section{Empirical Analysis}

\section{$2.1 \quad$ Data}

Our data set comprises the American states from 1960 to $2006 .{ }^{21}$ The majority of American states (thirty-four) give their governors line-item veto power and require a two-thirds majority in the legislature for this veto to be overridden. These state will form our restricted line-item veto sample. We also provide results for an extended line-item veto sample, in which we add states where the override requirement is $50 \%$ of the votes. Finally, we compare the results from the sample of states with line-item veto with the sample of states with block veto. ${ }^{22}$

Our variable for the tax level is taxes_GDP. It is defined as the sum of state income, corporate, and sales taxes divided by state GDP. In line with Persson and Tabellini (2004), we focus on the tax level relative to GDP. For our robustness checks we show results using the expenditure levels as an alternative measure of government size. Expenditure is not our preferred measure as it contains both federal transfers and local property taxes revenues, which are not decided at state level. The average tax level in an American state is around 5.5\% of GDP, whereas the average state expenditure level is around $10 \%$ of GDP. Another potential dependent variable would be transfers received by district. Unfortunately identifying district level expenditure is not easy. ${ }^{23}$ In particular, some targeted transfers may come in the form of tax cuts or exemptions.

\footnotetext{
${ }^{21}$ Most of our political, fiscal, and population variables are the same as those used by Besley and Case (2003). We are thankful to Timothy Besley and Anne Case for making their data sets available to us. We have updated their sample from 1960 to 1998 with data from 1999 to 2006. We have used data from the Census Bureau, the National Association of State Budget Offices (NASBO), and the National Conference of State legislatures (NCSL)

${ }^{22}$ In total there are 50 states. Most states have the line-item veto throughout, but some adopted it within the period covered by our sample (Iowa, Maine, Washington, West Virginia). These states enter the block veto sample up to adoption, at which point they move to the line-item veto sample. The block veto also includes the six states with the block veto throughout. These are Indiana, Nevada, New Hampshire, North Carolina, Rhode Island and Vermont. The extended line-item veto sample includes Alabama, Arkansas, Illinois, Kentucky, and Tennessee. California is excluded because it requires a twothird majority to approve the budget. We have also excluded Alaska, Hawaii, Nebraska, and Minnesota because of missing data. This leaves us with a restricted line-item veto sample of 1,524 observations; an extended line-item veto sample of 1712 observations; and a block veto sample of 287 observations.

${ }^{23}$ Some new data has been produced by Aidt and Shvets (2011). They are able to identify district level educations expenditure for seven states from 1993 to 2004. A future avenue of research is to use data on county specific transfers from the Census of Government. Ansolabehere and Snyder (2006) use this data and their results support the mechanism proposed in our model. They find that: ' $(\mathrm{x})$ counties that traditionally give the highest vote share to the governing party receive larger shares of state transfers to local governments; (ii) when control of the state government changes, the distribution of funds shifts in the direction of the new governing party.' The reason we have not pursued this further is that we would need to identify partisan support from state electoral results for state legislators organized by county, and this data does not seem readily available. Ansolabehere and Snyder (2006) identify partisan support at the county level using federal and gubernatorial elections.
} 
We do show results with an alternative measure for the tax level: state taxes per capita. However, it is important to note that taxes per capita is considerably less stationary than tax revenues over GDP. This can be seen in Table 1.

Table 1: Different measures of the states' tax level

\begin{tabular}{|c|c|c|c|c|c|}
\hline Measure & $1960 \mathrm{~s}$ & $1970 \mathrm{~s}$ & $1980 \mathrm{~s}$ & $1990 \mathrm{~s}$ & $2000 \mathrm{~s}$ \\
\hline \multicolumn{6}{|c|}{ States with the line-item veto } \\
\hline state taxes per capita (1982-dollars) & 346 & 588 & 673 & 838 & 911 \\
\hline state taxes over state GDP (\%) & 4.4 & 5.7 & 5.7 & 5.8 & 5.7 \\
\hline \multicolumn{6}{|c|}{ States with the block veto } \\
\hline state taxes per capita (1982-dollars) & 361 & 560 & 658 & 804 & 864 \\
\hline state taxes over state GDP (\%) & 4.6 & 5.6 & 5.7 & 5.6 & 5.4 \\
\hline
\end{tabular}

Note: The sample in the first three lines comprises 1524 observations of states with the line-item veto from 1960 to 2006 . In the bottom three lines the sample comprises 292 observations of state with the block veto from 1960 to 2006. Each observation represents a state within a year. The tax level is measured as the total sum of a state's income, sales, and corporate taxes. Each entry is the average of all observations within a decade.

Changes in the tax rates would have been another alternative for the dependent variable. We have not followed this strategy for two reasons. First, the tax level is progressive. As the economy grew over the period, the tax level would have increased in the long term without any changes in the tax rates. Changes in the tax level can be achieved without the introduction of any bill if the intended changes are in line with the business cycle. Second, we have not found detailed enough data on tax rate changes.

We have found detailed information on the adoption of income and corporate taxes in the period. This can be seen in Table 2. Of the seven states with the line-item veto that adopted a new tax in the period, only Ohio had a fully divided government. New Jersey had an aligned House, but a misaligned Senate. The remaining five states had a fully aligned government. This suggests that a new tax is more likely to be adopted under a fully unified government. Out of the four states with a block veto, two had a fully aligned government, and two had a fully divided government. This suggests that in the states with block veto, political alignment is not relevant in explaining the adoption of a new tax. Moreover, both in the states with the line-item veto and with the block veto the unified governments are evenly divided between Republicans and Democrats. Overall, Table 2 suggests that the adoption of new taxes during the sample period seems to be in keeping with the mechanism presented in our model and with the empirical results we describe below. 
Table 2: Political parties and the adoption of income and/or corporate taxes

\begin{tabular}{|c|c|c|c|}
\hline State and year & Majority in the House & Majority in the Senate & governor \\
\hline \multicolumn{4}{|c|}{ States with line-item veto } \\
\hline Connecticut (1970) & Democrat & Democrat & Democrat \\
\hline Florida (1972) & Democrat & Democrat & Democrat \\
\hline Illinois (1970) & Republican & Republican & Republican \\
\hline Michigan (1968) & Republican & Republican & Republican \\
\hline New Jersey (1962) & Democrat & Republican & Democrat \\
\hline Ohio (1972) & Republican & Republican & Democrat \\
\hline Pennsylvania (1971) & Democrat & Democrat & Democrat \\
\hline \multicolumn{4}{|l|}{ States with block veto } \\
\hline Indiana (1964) & Republican & Republican & Democrat \\
\hline Maine (1970) & Republican & Republican & Democrat \\
\hline Rhode Island (1970) & Democrat & Democrat & Democrat \\
\hline New Hampshire (1971) & Republican & Republican & Republican \\
\hline
\end{tabular}

Note: Our sample comprises data on corporate and income tax revenue from 1960 to 2006.

\subsection{The partially linear model: testing the non-linearities}

In this section we test the prediction made in proposition 1 . We are interested in the relationship between the tax level and a variable that we call Governor's strength. Governor's strength is defined as the percentage of seats that belong to the governor's party in the legislature - be the governor Republican or Democratic. Governor's strength will enter the model non-linearly, while state and year dummies, and other covariates will enter the model linearly. We allow for the estimated function to be discontinuous. We can then test whether the estimated discontinuity is significant.

The empirical variable Governor's strength is equivalent in our model to a variable we shall call $n_{l}$, which is defined as $s_{L} \times 100$ if the government is unified and $\left(1-s_{L}\right) \times 100$ if the government is divided. The variable $n_{l}$ in the model is simply the percentage of seats in the legislature that belong to the same party as the governor.

There are two chambers in each state. ${ }^{24}$ To estimate the non-linear relationship we define a government as divided if at least one chamber in the legislature is at the hands of the opposition to the governor. We, therefore, measure Governor's strength as being the minimum value between the percentage of seats held by the governor's party in the state House and in the state Senate. If the minimum is above $50 \%$, both chambers are aligned with the governor. If Governor's strength is below $50 \%$, the government is divided. ${ }^{25}$

\footnotetext{
${ }^{24}$ With the exception of Nebraska.

${ }^{25} \mathrm{~A}$ few observations have independent representatives. We define the Governor's strength based on the number of representatives belonging to the same party as the governor. Independent representatives
} 
The alternative definition would be to classify a government as unified as long as one chamber is aligned with the governor. The degree of alignment would then be defined as the maximum between the two legislative chambers. In Section A.6 on the on-line appendix we show that there is no jump in the tax level as we move from divided to unified government with this alternative definition. This is to be expected as a majority in the two chambers is necessary in order to approve the budget.

In Table 1, we see that the average tax level has remained stable since the 1970s. We interpret our estimation as capturing small deviations from the mean state tax level at each year.

We control for: state and year fixed effects; state population; state income per capita (in 1981 dollars); an indicator variable for whether the state has a supermajority requirement for a tax rate increase in that year; ${ }^{26}$ and an indicator variables for whether the state has expenditure limitations by law in that year. Our main concern is an omitted variable for the voters' political preferences and how they change overtime and across states; the tax level may be chosen in response to changes in these preferences. We therefore add three control variables as proxies for these preferences: a measure of turnout in the last election; an indicator variable for whether the last election was a midterm election or a general election; and an indicator variable for the political identity of the governor. Each observation is a state, denoted by $s$, in a year, denoted by $t$.

The partially linear model is summarized as:

$$
\text { taxes_GDP }_{\text {st }}=\beta^{\prime} X+f\left(\text { Governor's strength }_{s t}\right)+\epsilon_{s t},
$$

where all of the control variables mentioned in the above paragraph enter linearly in $X$ together with state and year dummies. The relationship between Governor's strength and the tax level is allowed to have a unspecified shape (restricted to be continuous except for the $50 \%$ cutoff). In Section 2.3.1 we discuss whether the discontinuity we estimate is valid as a regression discontinuity design.

The easiest way to estimate this model is to include a power series for the variable Governor's strength; one series for each side of the cutoff. To determine the degree of each series we stopped adding terms when the extra term was not precisely estimated. For the line-item veto sample, this procedure yields a quartic-polynomial to the left of

count as the opposition. Independent governors have values of Governor's strength $=0$ by definition as we can not identify the party identity of independent representatives. In the block veto sample we exclude 4 observations with perfectly tied legislatures, results are robust but less precise otherwise.

${ }^{26}$ For a detailed study on the effect of supermajority requirements on the tax level, see Lee et al. (2013). Note that the supermajority requirement is for a formal tax rate increase only, not decrease. Moreover, the tax level may increase as the economy grows since taxes are progressive. For these reasons it is not clear whether this supermajority requirement implies a different cutoff point for our purposes. We choose to keep these observations. All results are robust to excluding them. 
the $50 \%$ cutoff and a quadratic-polynomial to the right. For the block veto sample, this procedures yields a quadratic polynomial to the right of the cutoff and no precise estimate to the left of the cutoff (we therefore use a quadratic polynomial also on the left of the cutoff). ${ }^{27}$

The result of this procedure can be seen in Table 3 . In column 1 we can see the results for the line-item veto and in column 3 for the block veto. In order to estimate the size of the discontinuity and its standard error it is useful to normalize the function to take the value 0 at Governor's strength $=50 \%$. The estimate of the jump is at the bottom of Table 3 for each column. The results show a statistically significant increase in the tax level in the order of $7 \%$ at the $50 \%$ cutoff in the sample of states with the line-item veto. In the sample of states with the block veto, the point estimate indicates a decrease of less than $2 \%$ which is not statistically different from zero. These results are in line with the predictions of our model.

In Table 3 column 2, we can see that the shape of the relationship between Governor's strength and the state tax level is similar in an estimation without any controls or state and years fixed effects. ${ }^{28}$ In column 4 , we can see that the shape of the relationship in the block veto sample is not robust to an estimation without control variables and state and year fixed effects. However, the estimated discontinuity remains small and not statistically different from zero.

\footnotetext{
${ }^{27}$ In the online appendix Table 6 we show that the shape is not precisely estimated if we use higher order polynomial on either side of the cutoff.

${ }^{28}$ We have performed a series of robustness checks that are available on the on-line appendix, Section A.4. The shape and discontinuity of the function are robust to being estimated with state and year dummies only, with different combinations of controls, to excluding the observations in which a supermajority requirement for a tax increase is in place, to excluding the southern states, and to estimating the function with an alternative dependent variable: the state tax level per capita.
} 





A potential issue with the power series estimator is that it may be sensitive to the polynomial degree. We have therefore implemented a semiparametric procedure as presented by Robinson (1988). The linear part of the model is estimated as in any linear model. The non-linear part is estimated non-parametrically, so that we do not impose any restrictions on its actual shape. We use a local linear regression with a triangular kernel and the optimal bandwidth suggested by Imbens and Kalyararaman (2009).

For the line-item veto sample, the results of both the power series estimation in Table 3, column 1, and the semiparametric procedure can be seen in Figure $3 .^{29}$ The solid line plots the function estimated with the power series and the crosses are the point estimates of the semiparametric procedure. The dots are the local averages. In Figure 2 we plot the results of the power series estimator without any controls presented in Table 3 , column 2, and the results of a non-parametric estimate using a local-linear regression with a triangular kernel and the optimal bandwidth suggested in Imbens and Kalyararaman (2009). For the block veto sample, the parallel results can be seen in Figure 6 and Figure 5 .

In Figure 1 we have plotted the results of our theoretical model for the states with the line-item veto for a particular utility function $V(f)=f^{\frac{9}{10}}$ and a particular governor's support $s_{G}=0.57$ (or $57 \%$ of the seats). These parameters have been chosen to match the shapes of the semiparametric estimates for the line-item veto sample in Figure 3. Both the power-series and the semi/non-parametric estimates in Figures 3 and 2 lend support to the main features of our model. First, the estimates reveal a discontinuity in the tax level. Second, there is a negative relationship between the tax level and Governor's strength to the immediate left of the cutoff. To the right of the cutoff the relationship between the tax level and Governor's strength depends on the estimation method. The semiparametric methods indicates a concave function and the power-series estimators suggest a decreasing function. The concave function is rationalizable by our model the parameter $s_{G}>0.5$ and the decreasing function by a $s_{G}$ approaching 0.5 . A robust feature of the data seems to be that the tax level increases in a divided government as the opposing legislative majority increases around the cutoff (towards the left), that is, as the government becomes 'more divided'. This feature supports Proposition 1 in Section 1.1.

In Figure 4 we have plotted the results of our theoretical model for the states with the block veto with the same utility function: $V(f)=f^{\frac{9}{10}}$. The feature of no discontinuity in the tax level if verified in both the partially linear estimates in Figure 6 and in the

\footnotetext{
${ }^{29}$ If the density of Governor's strength is zero or close to zero at any point, the estimator is unreliable. We follow Robinson (1988) and solve this problem by trimming $1 \%$ of the lowest density points of Governor's strength. This trimming makes the sample in which we run the power series and the semiparametric method not identical. In the tables we have not performed the trimming, but we have for Figure 3. The estimates with and without trimming are virtually identical.
} 
States with the line-item veto:

Figure 1: Model prediction with $V(f)=f^{\frac{9}{10}}$

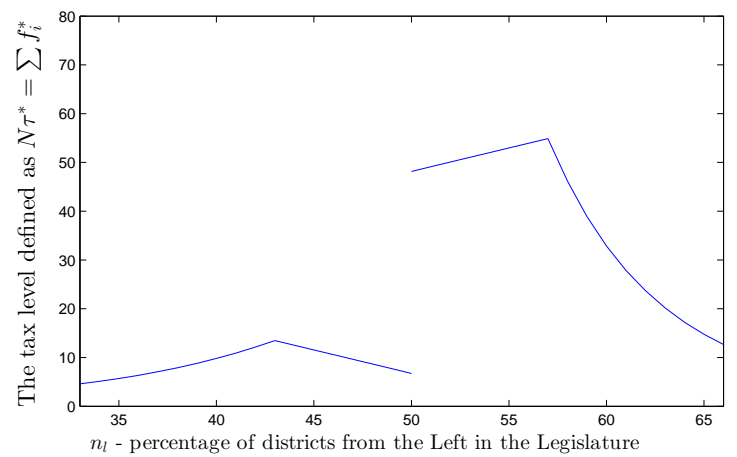

( $n_{g}=57$ - the Governor is from the Left with a support of $57 \%$ of the districts)
States with the block veto:

Figure 4: Model prediction with $V(f)=f^{\frac{9}{10}}$

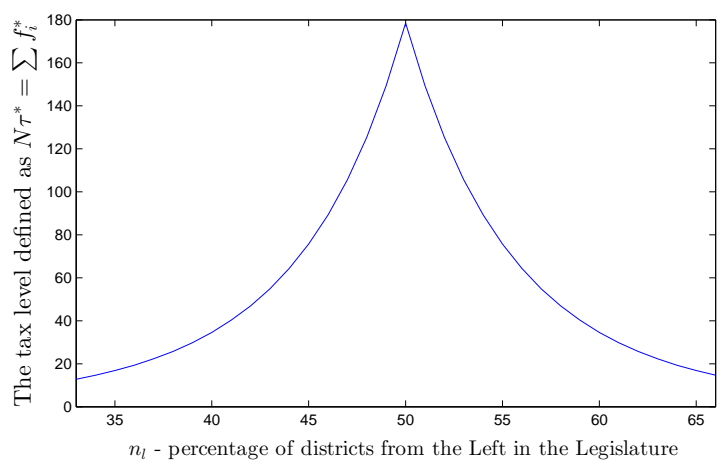

Figure 2: RDD non-parametric - poly.(4-3)



Figure 5: RDD non-parametric - poly.(2-2)

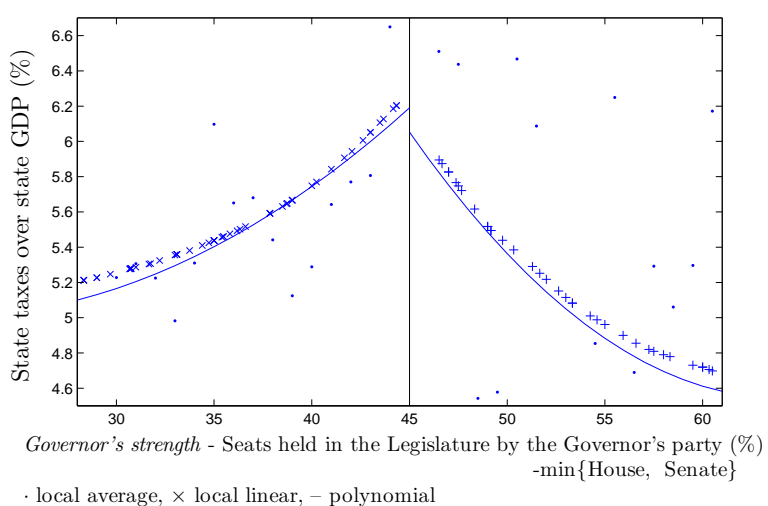

Figure 3: Partially linear estimation Semi- Figure 6: Partially linear estimation Semiparametric - poly.(4-2) parametric - poly. $(2-2)$

estimates with no controls in Figure 5. The shape of the function around the cutoff predicted by the model matches the empirical estimates without controls in Figure 5, but these shapes are not robust to the inclusion of state and year fixed effects and other controls. This lack of robustness may be due to small sample size. Note that our model predictions regarding the shape of the relationship in the states with the block veto depend on the degree of concavity of $V($.$) . The only clear predictions by the model$ regarding the relationship is the symmetry around the inflection point $\left(n_{l}=50\right)$ and the lack of a discontinuity in the tax level at the $50 \%$ cutoff. Both these features are robust in the data.

\subsection{Regression discontinuity design}

\subsubsection{Discontinuity estimates}

In this section we show that the $50 \%$ cutoff in Figures 3, 4, 5, and 6 are valid as regression discontinuity designs (the validity is more robust for the sample of states with the lineitem veto). Therefore, the jump in the tax level estimated for the states with the line-item veto has a causal interpretation, and so does the lack of a jump in the states with the block veto.

In the regression discontinuity design, the forcing variable is Governor's strength. Above the $50 \%$ cutoff, the observation receives treatment. The treatment is an "unified government". At each period, a state is either assigned the treatment or not. For the observations in which the elections delivered a slim majority in either chamber, we argue that the assignment of treatment was as if it were random. The identification assumption of the regression discontinuity design is only valid at the cutoff, where the forcing variable determines whether an observation receives treatment or not. All other covariates are assumed to be continuous at the $50 \%$ cutoff. If this is the case then the treatment status is solely determined by whether the government is divided or unified and we can read the jump in the tax level as a caused by the change in treatment status.

The identification assumptions of a regression discontinuity design are different to the assumptions necessary to estimate the shape of the relationship between the tax level and Governor's strength. For example, identification of the jump should not depend on the use of control variables. It is reassuring, therefore, that the results regarding the discontinuity for both the line-item veto and block veto states do not depend on the inclusion of control variables (see Table 3 ). 


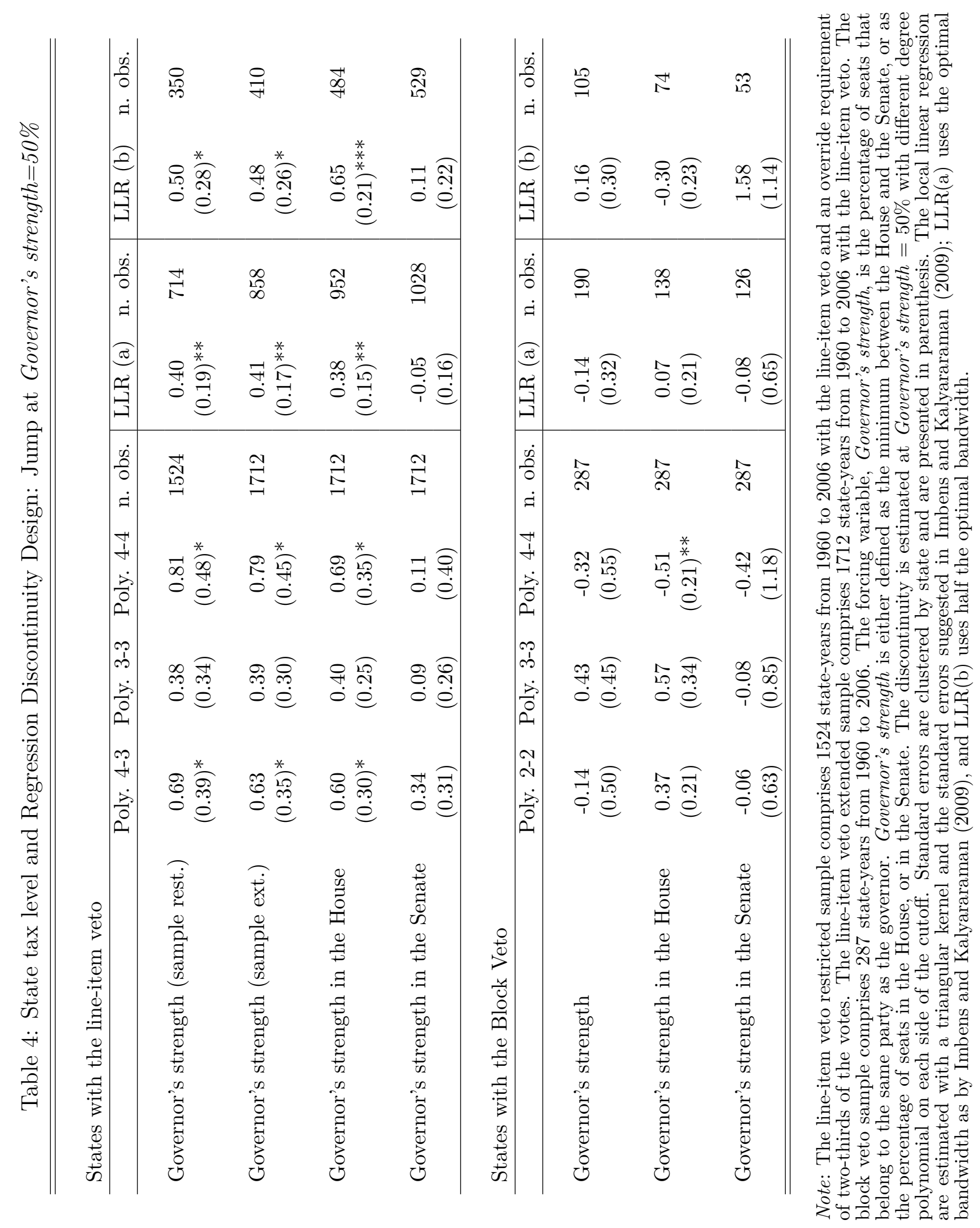


Since in this section we are not trying to identify the shape of the function elsewhere in the domain, the sample can be extended to all states with the line-item veto, whether or not they have a two-third override requirement. We will refer to this as the extended sample. Since our focus is on the jump at the cutoff and not the effect of changes in the degree of alignment, we can also look at each chamber separately. In Table 4 we show results for regression discontinuity estimates for the line-item veto and block veto samples. We estimate the discontinuities with different polynomial degrees and using a local linear regression.

In Table 4, rows 1 and 2, we can see that the discontinuity in the tax level is robust whether we use the restricted or the extended sample of line-item veto states. The estimates are significant as long as we allow for enough flexibility to the left of the cutoff; a quartic polynomial is required to pick up the drop in the function as it approaches the cutoff. In columns 4 and 5 we present non-parametric estimates, which consist of a local linear regression (LLR). LLR(a) uses the optimal bandwidth suggested by Imbens and Kalyararaman (2009) and LLR(b) uses half the optimal bandwidth. The result of a positive and significant discontinuity is robust wether we define the forcing variables as the minimum support for the governor between the House and the Senate (rows 1 and 2), or as the governor's support in the House alone (row 3). The alignment between the Senate and the governor seems to have no effect on the tax level (row 4).

In Table 4, rows 5 to 7 , the results indicate no jump in the tax level at the $50 \%$ cutoff for the states with the block veto, whether we define the forcing variables as the minimum support for the governor between the House and the Senate, the House alone, or the Senate alone. The sample size is much smaller however and the point estimates vary considerably depending on parametric or bandwidth choices. In the case of a quartic polynomial on either side of the cutoff, the discontinuity is estimated to be negative and significant, but this result is by no means robust.

It is interesting to compare the result in In Table 4, row 3, with the results in De Magalhães (2011), where the author presents a regression discontinuity estimate in the same sample but where the forcing variable is the percentage of seats the Democrats have in the state House. De Magalhães (2011) finds no jump in the tax level at the 50\% cutoff point, which indicates no causal relationship between the partisan control of the state House and the tax level. Considering our result and the result in De Magalhães (2011) it seems that the tax level, at least locally at the cutoff, is determined by whether the government is divided or unified, and not by whether Democrats or Republicans are in power. 


\subsubsection{Checking the validity of the design}

The main test of validity for a regression discontinuity design is to check if any covariate is discontinuous at the $50 \%$ cutoff. Under the identification assumption all unobservable and observable variables should be continuous at the cutoff. In Table 5 we present balance tests for a series of covariates. Democratic governor takes value 1 if the governor is a Democrat, and value 0 otherwise. Turnout is defined as the fraction of the population that turned out to vote in the last election. Midterm election takes value 1 if the election for that observation was a midterm election, and value 0 if the governor was also chosen in that election. Population is the state population in millions for a given year. Income per capita is the state income per capita in thousands of 1982-dollars. Unemployment rate is the state unemployment rate in a year. Local property taxes is the percentage of a state average property tax in a year divided by state GDP. Supermajority requirements takes value 1 if the state in that year requires a supermajority to vote for a formal tax increase. Tax and expenditure limitations takes value 1 if the state has a tax limitation rule on that year, and value 0 otherwise. The last row presents the McCrary (2008) test for a discontinuity in the density of the forcing variable.

In the case the forcing variables is the Governor's strength in the House we also check the continuity of the following variable (row 1): Governor's party control Senate, which is an indicator variable that takes value 1 if the majority in the Senate belongs to the governor's party, and value 0 otherwise. The lack of a discontinuity in this variable indicates that the variation in alignment between the House and the governor is not confounded by the alignment of the Senate. Likewise, in the case the forcing variables is the Governor's strength in the Senate we also check the continuity of the variable Governor's party control House (row 2).

Note that in Table 5, Row 3, observations on both sides of the cutoff are equally likely to have a Democratic governor or a Republican governor. This is important. If this were not the case we would be unable to separately identity the effect of a unified government versus a partisan effect.

In Table 5 we can see that for the states with the line-item veto there are no covariates that present a statistically significant discontinuity that is robust to different parametric specifications. This is true whether the forcing variable is Governor's strength defined as the minimum between the House and the Senate, Governor's strength in the House alone, or Governor's strength in the Senate alone. The only result that questions the validity of the design in the sample of line-item veto states is a significant discontinuity at the density of the forcing variable Governor's strength in the Senate. This discontinuity may indicate a capacity of voters to manipulate the partisan control of the Senate at the cutoff. The estimate is only significant at the $10 \%$ level and since there are no imbalances 
among the other variables, we do not see this as a clear refutation of the validity of the design.

The balance tests for the states with the block veto do not show any significant and robust discontinuity except for the variables population and turnout, and only in the case the forcing variable is Governor's strength defined as the minimum between the House and the Senate. However, when the population and turnout variables are tested for imbalances for the House and Senate separately, no significant and robust discontinuity is found. Once again we do not see this as a clear refutation of the validity of the design.

Overall, the regression discontinuity design seems valid and we can interpret the jump in the tax level at the $50 \%$ cutoff in the sample of states with the line-item veto as the causal result of a move from a divided to a unified government. The results in Tables 4 and 5 show that the RDD for the state Houses is particularly robust. ${ }^{30}$ This does not mean that the alignment between the Senate and the governor has no effect on the tax level. The Senate may still play an important role in determining how the degree of alignment affects the tax level away from the cutoff, for this reason we did not discard the Senate in the estimates of the partially linear model in Section 2.2.

\footnotetext{
${ }^{30}$ In the online appendix, Section A.7 we show that the discontinuity estimated in Table 4 in the states with the line-item veto is robust to the exclusion of any state, of any decade, and also that only the discontinuity at $50 \%$ is significant.
} 







\section{Concluding Remarks}

In our model we have described how in the American states with the line-item veto, the structure of the bargaining game between the governor and the legislature implies budgetary separation of powers. By budgetary separation of powers we mean that the branch responsible for setting the tax level is not the full residual claimant of a tax increase. This is the 'sting' of the line-item veto (see Carter and Schap (1990)). With the line-item veto the governor can prevent the legislative branch from appropriating the tax proceeds as a residual claimant.

We also find evidence, in the context of the American states, for the hypothesis in Persson et al. (2000) that the tax level should be lower in the case there is separation of powers. This is an important contribution because the empirical evidence supporting this hypothesis in the cross country setting is not strong; see Persson and Tabellini (2004), Acemoglu (2005), and Blume et al. (2009).

We go beyond Persson et al. (2000), by showing that the effectiveness of this formal separation of powers varies with the political configuration. The governor will only veto the budget proposal from a misaligned legislative majority. The effectiveness of the budgetary separation of powers varies in strength according to the degree of political alignment between the vetoing branch and the proposing branch. Budgetary separation of powers in the US states is not a categorical definition, but may vary in intensity according to the political conflict between branches.

Finally, we have found empirical evidence that, when made effective by the presence of the line-item veto, the budgetary separation of powers does have a negative causal effect on the tax level. There is a clear jump in the tax level as the government moves from unified to divided in the states with the line item veto: taxes go down. 


\section{References}

Abrams, B. A. and Dougan, W. R. (1986). The effects of constitutional restraints on government spending. Public Choice, 49(2):101-16.

Acemoglu, D. (2005). Constitutions, politics and economics: A review essay on Persson and Tabellini's "The Economic Effect of Constitutions". Journal of Economic Literature, 43(4):1025-1048.

Aidt, T. and Shvets, J. (2011). Distributive politics and electoral incentives: Evidence from seven US state legislatures. CesIfo Working paper no. 3405.

Alemán, E. and Schwartz, T. (2006). Presidential vetoes in Latin America. Journal of Theoretical Politics, 18(1):98-120.

Alesina, A. and Rosenthal, R. (1996). A theory of divided government. Econometrica, 64(6):1331-1341.

Alm, J. and Evers, M. (1991). The item veto and state government expenditure. Public Choice, 68(1-3):1-15.

Alt, J. E. and Lowry, R. C. (1994). Divided government, fiscal institutions, and budget deficits: Evidence from the states. American Political Sience Review, 88(4):811-828.

Ansolabehere, S. and Snyder, J. M. J. (2006). Party control of state government and the distribution of public expenditures. The Scandinavian Journal of Economics, 108(4):547-569.

Besley, T. and Case, A. (2003). Political institutions and policy choices: Evidence from the United States. Journal of Economic Literature, 41(1):7-73.

Blume, L., Muller, J., Voigt, S., and Carsten, W. (2009). The economic effects of constitutions: replicating - and extending - Persson and Tabellini. Public Choice, 139:197-225.

Bohn, H. and Inman, R. (1996). Balanced budget rules and public deficits: Evidence from the U.S. National Bureau of Economic Investigation Working Paper, 5333.

Carter, J. R. and Schap, D. (1990). Line-item veto: Where is thy sting? Journal of Economic Perspectives, 4(2):103-118.

Cox, G. and McCubbins, M. (1986). Electoral politics as a redistributive game. Journal of Politics, 48:69-95. 
de Figueiredo Jr., R. J. P. (2003). Budget institutions and political insulation: why states adopt the item veto. Journal of Public Economics, 87(12):2677-2701.

De Magalhães, L. M. (2011). Political parties and the tax level in the American states: A regression discontinuity design. University of Bristol, Economics Department Discussion Paper No. 10/614.

Dearden, J. A. and Husted, Thomas, A. (1993). Do governors get what they want?: An alternative examination of the line-item veto. Public Choice, 77:707-723.

Dixti, A. and Londgren, J. (1995). Redistributive politics and economic efficiency. American Political Science Review, 89:856-866.

Dixti, A. and Londgren, J. (1998). Ideology, tactics, and efficiency in redistributive politics. Quarterly Journal of Economics, 113(2):497-529.

Ferreira, F. and Gyourko, J. (2009). Do political parties matter? Evidence from U.S. cities. The Quarterly Journal of Economics, 124(1):399-422.

Gerber, E. R. and Hopkins, D. J. (2011). When mayors matter: Estimating the impact of mayoral partisan on city policy. American Journal of Political Science, 55(2):326-339.

Grossman, G. M. and Helpman, E. (2008). Separation of powers and the budget process. Journal of Public Economics, 92:407-425.

Holtz-Eakin, D. (1988). The line item veto and public sector budgets: Evidence for the states. Journal of Public Economics, 36:269-292.

Imbens, G. and Kalyararaman, K. (2009). Optimal bandwidth choice for the regression discontinuity estimator. NBER Working Paper 14726.

Lee, D., Borcherding, T. E., and Kang, Y. (2013). Public spending and the paradox of supermajority rule. Southern Economic Journal.

Leigh, A. (2008). Estimating the impact of gubernatorial partisanship on policy settings and economic outcomes: A regression discontinuity approach. European Journal of Political Economy, 24:256-268.

Lindbeck, A. and Weibull, J. (1987). Balanced-budget redistribution as the outcome of political competition. Public Choice, 51:272-297.

McCarty, N. M. and Poole, K. T. (1995). Veto power and legislation: An empirical analysis of executive and legislative bargaining from 1961 to 1986. Journal of Law, Economics, and Organization, 11(2):282-312. 
McCrary, J. (2008). Manipulation of the running variable in the regression discontinuity design: A density test. Journal of Econometrics, 142(2):698-714.

Meyers, R. T. (1997). Late appropriation and government shutdowns: frequency, causes, consequences, and remedies. Public Budgeting and Finance, 17:25-38.

Myerson, R. (1993). Incentives to cultivate minorities under alternative electoral systems. American Political Science Review, 87:856-869.

Persson, T., Roland, G., and Tabellini, G. (2000). Comparative politics and public finance. The Journal of Political Economy, 108(6):1121-1161.

Persson, T. and Tabellini, G. (2004). Consitutional rules and fiscal policy outcomes. The American Economic Review, 94(1):25-45.

Poterba, J. (1994). State responses to fiscal crisis: The effects of budgetary institutions and politics. The Journal of Political Economy, 102(4):799-821.

Reed, W. R. (2006). Democrats, republicans, and taxes: Evidence that political parties matter. Journal of Public Economics, 90(4-5):725-750.

Robinson, P. M. (1988). Root-n-consistent semiparametric regression. Econometrica, 56(4):931-954.

Schmalensee, R. and Stoker, T. M. (1999). Household gasoline demand in the United States. Econometrica, 67(3):645-662.

Tsebelis, G. (2002). Veto Players: How Political Institutions Work. Princeton University Press.

Tsebelis, G. and Rizova, T. P. (2007). Presidential conditional agenda setting in the former communist countries. Comparative Political Studies, 40(10):1155-1182.

Warren, P., Fredriksson, P., and Wang, L. (2013). Party politics, governors, and economic policy. Southern Economic journal, Forthcoming. 


\section{A Online Appendix}

\section{A.1 Proofs}

We present an extensive proof for lemma 1, and shorter versions for the remaining proofs.

Lemma 1.1 (Proof) At the last stage, the governor faces three constraints (see equation 3): the nonnegativity constraints, the budget constraint, and the proposed transfers $f_{(x) L}$ as upper bounds. ${ }^{31}$ The Lagrange function is:

$W^{G}\left(\tau, f_{(x)}, \mu_{G}, \lambda_{(x) G}, \eta_{(x) G}\right)=\int_{x \in G} v_{(x)} d x+\mu_{G}\left[\tau-\int_{x} f_{(x)} d x\right]+\int_{x} \eta_{(x) G}\left[f_{(x) L}-f_{(x)}\right] d x+\int_{x} \lambda_{(x) G} f_{(x)} d x$

where $\mu_{G}$ is the standard budget constraint lagrange multiplier, $\lambda_{(x) G}$ is for the nonnegativity constraint of each district program, and $\eta_{(x) G}$ is for each upper bound on each transfer - given that the governor cannot raise but only trim them down. Summarizing, the first order conditions on a generic $f_{(x)}$ for any $x \in G$, for $\tau$, and for the relevant constraints are respectively:

$$
\begin{array}{r}
V^{\prime}\left(f_{(x)}\right)-\mu_{G}-\eta_{(x) G}+\lambda_{(x) G}=0 \\
s_{G}=\mu_{G}, \\
\eta_{(x) G}\left[f_{(x)}-f_{(x) L}\right]=0=\lambda_{(x) G} f_{(x)}
\end{array}
$$

Thus, for any $0 \leq f_{(x) G} \leq f_{(x) L}, \eta_{(x) G}=\lambda_{(x) G}=0$ and $V^{\prime}\left(f_{(x)}\right)=s_{G}$, which yields the same bliss level for any $x \in G: f_{(x) G}=V^{-1}\left(s_{G}\right)=f\left(s_{G}\right)$. If, instead, $V^{-1}\left(s_{G}\right)>f_{(x) L}$ then the second constraint is binding with $\eta_{(x) G}>0$ and $f_{(x) G}=f_{(x) L}$. We find two cases here: one in which $0<f_{(x) L}$ and another with $f_{(x) L}=0$.

Summarizing, for any $x \in G$ and given $f_{(x) L}$ from the previous stage, we may have three alternative outcomes: a) $f_{(x) G}=f\left(s_{G}\right)$ if $f\left(s_{G}\right) \leq f_{(x) L}$, b) $f_{(x) G}=f_{(x) L}>0$ if $f_{(x) L}$ is positive but $f_{(x) L} \leq f\left(s_{G}\right)$ and, c) $f_{(x) G}=f_{(x) L}=0$.

For $x \notin G$, equation (A.2) takes the form

$$
-\mu_{G}+\lambda_{(x) G}=0
$$

as $\lambda_{(x)}=\mu_{G}=s_{G}>0$ it holds that $f_{(x) G}=0$, using the second equality in (A.4) with a binding nonnegativity constraint. Transfer programs are pure cost for any district outside $G$. Thus, for any $x \notin G$, the districts specific spending programs will be zero, either by trimming down $f_{(x) L}>0$ or passing on the $f_{(x) L}=0$.

\footnotetext{
${ }^{31}$ Alternatively, the reader could substitute for $\tau$ in the utility function (1) using the government budget constraint. The constraint is going to be binding in equilibrium given the traditional assumptions on $v$.
} 
At the legislative stage, the majority foresees how the executive is going to react to her proposals, $f_{(x) L}$. The legislative majority faces an analogous objective function to (A.1). If the legislative majority actually takes into account the governor's equilibrium strategies, in addition to the budget and nonnegativity constraints, there is also an upper bound given by $f_{(x) G}$. Analogously, if we use these constraints explicitly, we incorporate three sets of Lagrange multipliers: $\mu_{L}$ for the budget constraint, $\eta_{(x) L}$ for the upper bounds, and $\lambda_{(x) L}$ for the nonnegativity constraints.

Using the parallel structure of the problem, for $s_{G} \leq s_{L}$ then $0 \leq f\left(s_{L}\right) \leq f\left(s_{G}\right)$, $\eta_{(x) L}=\lambda_{(x) L}=0$ and $V^{\prime}\left(f_{(x) L}\right)=s_{L}$, which yields the same bliss level for any $x \in L$ : $f_{(x) L}=V^{-1}\left(s_{L}\right)=f\left(s_{L}\right)$. Alternatively, it may be the case that $f\left(s_{L}\right)>f\left(s_{G}\right)>0$, then the second constraint binds, with $\eta_{(x) L}>\dot{0}$. This yields $f_{(x) L}=f\left(s_{G}\right)$. As discussed above, note that if we did not take into account the upper bound $f\left(s_{G}\right)$, the governor would still trim $f_{(x) L}$ back down. In any case, the outcome is the same. And, finally, $f_{(x) G}=0$ for any $x \notin G$ and $x \in L$ this acts as a binding constraint again. Thus, any $f_{(x) L} \in\left[f_{G}^{*}, \infty\right)$ for $f_{G}^{*} \in\left\{0, f\left(s_{G}\right)\right\}$ and $f\left(s_{G}\right) \leq f\left(s_{L}\right)$, are (payoff equivalent) equilibrium strategies for the legislative majority.

For all $x \notin L$, the majority's first order conditions change to $-\mu_{L}+\lambda_{(x) L}=0$, with $\lambda_{(x) L}=\mu_{L}>0$, and $f_{(x) L}=0$. Transfer programs are pure cost for any district outside $L$.

Summing up, districts outside the support of either constituency receives zero transfers in equilibrium. Only districts that are in the overlapping set $(G \cap L)$ will receive positive transfers in equilibrium. Formally, the governor implements transfers, $f_{G}$, that satisfy the following:

$$
f_{(x) G}=\left\{\begin{array}{c}
\min \left\{f\left(s_{G}\right), f\left(s_{L}\right)\right\} \text { for any } x \in G \cap L \\
0 \text { otherwise. }
\end{array}\right.
$$

Note that the optimal level of transfers for those districts that do receive positive transfers does not depend on the size of the overlap. The amount each district gets only depends on the size of the governor's support $s_{G}$ or the size of the legislative majority $s_{L}$. This implies that the legislative majority can solve an unconstrained maximization, i.e. simply assign $f_{(x) L} \geq f\left(s_{L}\right)$ to every district in $L$ and $f_{(x) L}=0$ for every district not in $L$, and let the governor trim any transfers to those districts not in the overlap (and trim those in the overlap if necessary). This result is due to the separability between $\tau$ and $f$, and the linearity of $\tau$ in the utility function.

Lemma 1.2 (Proof). We assume without loss of generality that the governor belongs to party $D$ and that $\frac{1}{2}<s_{G}<1$. Under a unified government, and given the ideological 
ordering in the line, all $x \in\left[0, s_{L}\right] \supseteq[0,0.5]$ make up party $D$ legislative majority, all $x \in\left[0, s_{G}\right] \supseteq[0,0.5]$ are part of party $D$ legislative majority. Therefore, under a unified government the size of the overlapping set is $\min \left\{s_{G}, s_{L}\right\} \geq \frac{1}{2}$.

Under a divided government, continuing with the case of a party $D$ governor, party $R$ holds the majority in the legislature. In this case, only $1-s_{L}<\frac{1}{2}$ districts support party $D$ legislators in the minority while the set of districts in the majority is given by $\left[s_{L}, 1\right] \supseteq[0.5,1]$. The size of the overlap of the active players is given by those that have a split representation in a divided configuration: the fraction of the districts in $G$, party $D$ governor's constituency, that also support party $R$ in the legislature. Formally, the size of the overlap is $s_{G}-\left(1-s_{L}\right)>0$ under a divided configuration. (Those are districts in the governor's support that are not in her minority party in the legislature.)

Within each configuration, the degree of alignment is a smooth continuous function in the share of districts in the legislative majority. However, this is not the case when the majority party switches in the legislature, at $\frac{1}{2}$. Under alignment the overlap is given by the smaller majority, $\min \left\{s_{G}, s_{L}\right\}=s_{L}=\frac{1}{2}$. But under divided it goes arbitrarily close to $s_{G}-\frac{1}{2}$.

The jump is $\Delta=1-s_{G}$. The discontinuity is present unless the governor has $100 \%$ of support. Only in this limiting case a switch from divided to unified government implies no change in the number of districts in the overlapping interval. Instead, with $s_{G}$ near $\frac{1}{2}$, the jump in the overlapping set is maximum, $\frac{1}{2}$.

Proposition 1 (Proof). Lemma 1 implies that in the states with line-item veto, the key determinant of the level of transfers is the mass of districts that belong to the constituency of both the governor and the legislative majority. Additionally, we have proved also in the same lemma that the level of transfers to each district in $G \cap L$ is pinpointed by the size of the larger constituency. Intuitively, the branch with the larger constituency internalizes more negative effects of taxation. Restating, note that given the strict concavity in $V(\cdot)$ :

$$
f\left(s_{L}\right)=V^{-1}\left(s_{L}\right) \gtreqless f\left(s_{G}\right)=V^{-1}\left(s_{G}\right) \Longleftrightarrow s_{L} \lesseqgtr s_{G} .
$$

To prove part $a$ ), now note that for slim majorities, $s_{L} \leq s_{G}$ and thus $f_{G}=f\left(s_{G}\right)$, for any $x \in L \cap G$. Equilibrium taxes are a function of both the level of each transfer and the share of recipient districts. Under a unified government, for any $s_{L}$ sufficiently near the cut off, taxes are $s_{L} f\left(s_{G}\right)$, since $\min \left\{s_{L}, s_{G}\right\}=s_{L}$ is the size of the recipient districts and $f\left(s_{G}\right)$ the size of each program; this is a linear increasing function in $s_{L}$ near the cutoff.

Under a divided government, taxes are $\left(s_{G}-\left(1-s_{L}\right)\right) f\left(s_{G}\right)$. As the size of the 
majority approaches the cutoff from the left, it gets smaller, and so does the size of the overlap as $\lim _{s_{L} \rightarrow \frac{1}{2}} s_{G}-\left(1-s_{L}\right)=s_{G}-\frac{1}{2}$.

As $s_{L}$ approaches $\frac{1}{2}$ we have:

$$
\tau_{\left(\frac{1}{2} ; s_{G}\right)}^{L I V}=\left\{\begin{array}{c}
\frac{1}{2} f\left(s_{G}\right) \quad \text { under a unified government } \\
\left(s_{G}-\frac{1}{2}\right) f\left(s_{G}\right) \text { under a divided government. }
\end{array}\right.
$$

Thus, $\Delta \tau=\left(1-s_{G}\right) f\left(s_{G}\right)>0$ for any $s_{G}<1$.

For part (b) we need to show that taxes are strictly increasing in the interval $\left[\frac{1}{2}, s_{G}\right)$ and for part $(c)$ strictly decreasing in the interval $\left[s_{G}, 1\right]$. These are straightforward given the previous proofs. In the interval $\left[\frac{1}{2}, s_{G}\right)$, taxes are $s_{L} f\left(s_{G}\right)$, increasing linearly in $s_{L}$. In $\left[s_{G}, 1\right]$ each transfer is pinpointed by $f\left(s_{L}\right)$ since now $s_{G}<s_{L}$ and the size of the overlapping set is fixed, determined by the min function at $s_{G}$. Thus, $\tau^{*}=s_{G} f\left(s_{L}\right)$ with $\frac{\partial \tau}{\partial s_{L}}=\frac{s_{G}}{V^{\prime \prime}\left(s_{L}\right)}<0$.

Finally, we are left with part (d), which claims that under a divided government taxes are strictly decreasing for $s_{L}<s_{G}$ and part (e) with an ambiguous tax level behaviour for $s_{G}<s_{L}$. For $s_{L}<s_{G}, f_{G}=f\left(s_{G}\right)$ and the overlapping set shrinks as the majority in the legislature gets smaller, approaching $\frac{1}{2}$. For $s_{G}<s_{L}, f_{G}=f\left(s_{L}\right)$ which increases as $s_{L}$ lowers, but the overlapping set increases. Formally, $\frac{\partial \tau^{*}}{\partial s_{L}}=\frac{s_{G}-\left(1-s_{L}\right)}{V^{\prime \prime}\left(f\left(s_{L}\right)\right)}+f\left(s_{L}\right) \lesseqgtr 0$.

Proposition 2 (proof). Under block veto, all the action is driven by $s_{L}$. To see this, first we need to show that it is too costly for the governor to exercise a block veto. Consider the extreme case in which taxation to fund transfers carries no benefit to $G$ : a divided configuration with $s_{G}=s_{L}=1 / 2$. All transfers that amount $\tau$ are pure costs to the governor, according to (3). Under line-item veto, all transfers would be trimmed down to zero. This would increase the governor's welfare by $\frac{1}{2} f\left(\frac{1}{2}\right)$ as taxation would decrease by $f\left(\frac{1}{2}\right)$, the reduction in spending programs for all districts in $[0.5,1]$ outside $G$. However, the block veto paralyzes the whole budget, therefore loosing the net benefits $H(\bar{g})-\tau^{g}$, per capita and per district. The aggregate loss is then $\frac{1}{2}\left[H(\bar{g})-\tau^{g}\right]$. The net benefit is negative as $H(\bar{g})-\tau^{g}>V^{-1}\left(\frac{1}{2}\right)$, by assumption. The overall level of taxation is then driven by

$$
\tau^{B V}=\int_{x \in L} f_{(x) L}\left(s_{L}\right) d x=s_{L} f\left(s_{L}\right),
$$

with $s_{L} \in[0.5,1]$ continuous for any party configuration. Thus the size of the majority pins down both the set of beneficiaries and the level of transfers. Taxes feature a the mirror image, to the left and right of the threshold 0.5. Note that $\frac{\partial \tau}{\partial s_{L}}=\frac{s_{L}}{V^{\prime \prime}\left(f\left(s_{L}\right)\right)}$ $+f\left(s_{L}\right) \lesseqgtr 0$, as $V^{\prime \prime}(\cdot)<0$. 


\section{A.2 Extending the model to include the intervals $\left[0, \frac{1}{3}\right]$ and $\left[\frac{2}{3}, 1\right]$}

In this session we consider the possibility of legislative overrides of executive vetoes. In Section 1 we have focused on the interval $s_{L} \in\left(\frac{1}{3}, \frac{2}{3}\right)$. Outside this interval, if we assume that veto overrides are costless, the governor plays no role. The results regarding the states with the block veto, presented in Proposition 2, carry through for the states with the line item veto in the intervals $s_{L} \in\left[0, \frac{1}{3}\right]$ and $s_{L} \in\left[\frac{2}{3}, 1\right]$. This implies that the model predicts a jump in the tax level as the legislative majority crosses the two-third threshold, be it with a divided or a unified government. This is because the governor can no longer prevent any district in the majority from receiving positive transfers. The model predicts a discontinuity in the tax level for all values of $s_{G}$ with one exception: if the government is unified and $s_{G}=\frac{2}{3}$.

In Figure 8 we show the shape estimated by the partially linear model in the whole support. Figure 8 is the same as Figure 3, but zoomed out. Most of the data (60\%) is concentrated in the interval where the override is not active, with the highest density around the $50 \%$ cutoff. The low data density in the extremes make it hard to implement a regression discontinuity design at Governor's strength $=33.3 \%$ or at Governor's strength $=66.6 \% .{ }^{32}$ We have found no statistically significant discontinuities in the tax level in these two cutoff points. For this reason, the estimates in Figure 8 impose continuity except for the $50 \%$ cutoff.

Even though there is no discontinuity in the tax level, there are clear inflections points at both Governor's strength $=33.3 \%$ and at Governor's strength $=66.6 \%$. These inflection points suggest that the veto override thresholds do play a role. A simple extension of the model can account for the shapes we see in Figure 8. In this extension we allow for another two types of transfers, besides $f_{(x)}$. These transfers behave according to a simple common pool problem, and we think of these transfers as pork-barrel, or the cost of doing business. This common pool element brings the simple intuition that large majorities bring the tax level up. We assume that if a district is part of the legislative majority it appropriates the same fixed amount $l_{(x)}$ as all other districts in the majority, regardless of the political configuration. Likewise, we assume that the governor is able to transfer the same amount $g_{(x)}$ to each district in the governor's support, even if a divided government is in place. These transfers are not affected by the governor's veto power. ${ }^{33}$ Depending on the relative importance of these common pool goods they imply

\footnotetext{
${ }^{32}$ At the extremes other issues may also play a role. For example, $85 \%$ of observations with Governor's strength $>66.6 \%$ are unified Democratic governments. In the rightmost extreme it would be difficult to disentangle partisan effects from institutional effects, as the sample is not balanced between republicans and democrats.

${ }^{33}$ Note that the common pool goods do not generate a discontinuity in the tax level at the $50 \%$ cutoff. At the cutoff, $50 \%$ of districts receive $l_{(x)}$ no matter whether the government is divided or unified.
} 
an increase in the tax level even as a increase in the majority may be lowering the level of $f_{(x)}$ given the concavity of the function $V($.$) .$

Keeping the functional form we have chosen in Figure 1, section $2.2\left(V=f^{\frac{9}{10}}\right)$, we add two linear transfers with values $l_{(x)}=170$ and $g_{(x)}=100 .{ }^{34}$ The main features we observe in Figure 1, Section 2.2, are present in Figure 7. The added feature are that taxes are increasing as we move to the right in the interval $(66 . \overline{6}, 100)$ and as we move to the left in the interval $(0,33 . \overline{3})$. The extended model presented in this section is able to match the shape estimated by the partially linear model in the whole support, which can be seen in Figure 8.

\footnotetext{
${ }^{34}$ To plot the model we assume there are 100 districts and that the governor has the support of 57. We plot the implied tax level by the model for different values of $s_{L}$.
} 
Figure 7: Model prediction with $V(f)=f^{\frac{9}{10}}, g_{i}=100$, and $l_{i}=170$

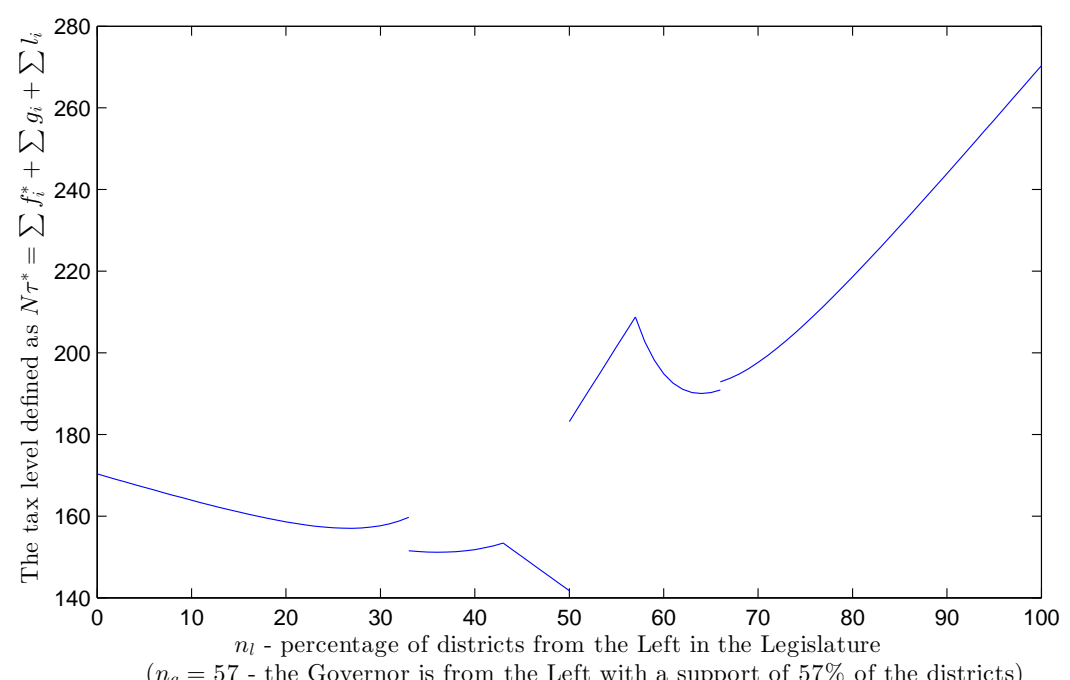

( $n_{q}=57$ - the Governor is from the Left with a support of $57 \%$ of the districts)

Figure 8: Partially linear estimation - poly.(4-2)

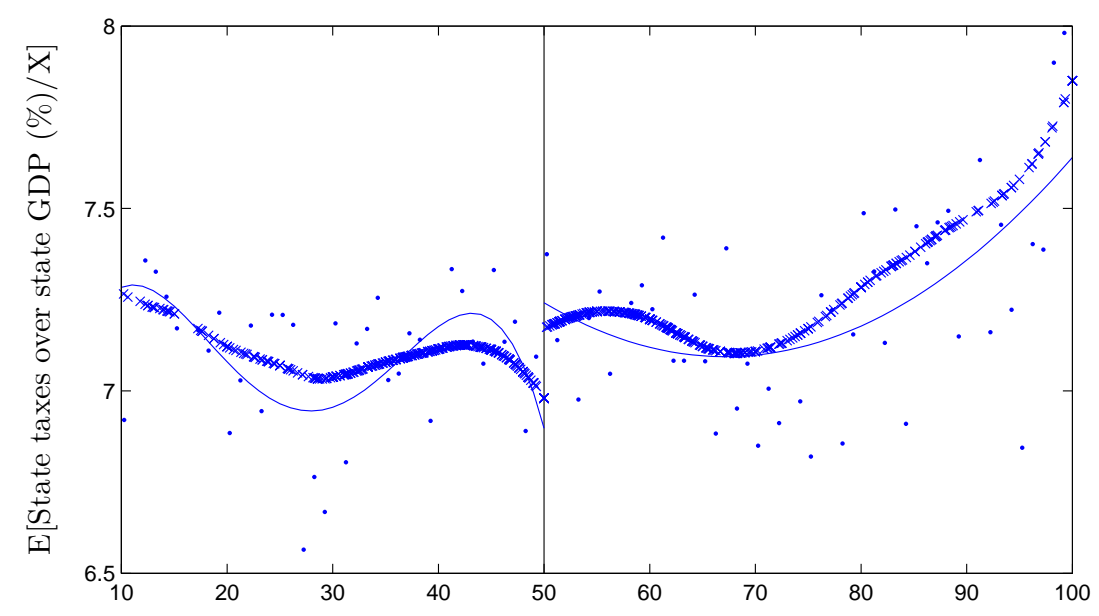

Governor's strength: seats held in the Legislature by the Governor's party (\%) - $\min \{$ House, Senate\} $\cdot$ local average, $\times$ local linear, - polynomials 


\section{A.3 Alternative setup with non-targetable spending items}

In this version of the model there are no specific transfers, $f_{(x)}$. The budget is now divided into two types of general spending items: $g_{1}$ and $g_{2}$, with $g=g_{1}+g_{2} \in \mathbb{R}_{+}$. Individuals or groups have heterogeneous preferences over these two spending programs. We capture the relevant source of heterogeneity with the parameter $\alpha_{i} \in[0,1]$, the relative preference intensity for spending $g_{1}$. We assume that $\alpha_{(x)}$ is ordered from left to right in the $[0,1]$ segment, with $\alpha_{(x)}=x, \alpha_{(0)}=0$ and $\alpha_{(1)}=1$. Districts on the left prefer good $g_{2}$ more than $g_{1}$ and districts on the right prefer $g_{1}$ more than $g_{2}$. Only the mean/meadian group has balanced preferences over both types of programs, $\alpha_{(1 / 2)}=\frac{1}{2}$. As in the main text, we assume that groups that have chosen party $D$ are to the left of those that have chosen party $R$ on the $[0,1]$ segment. This means that $g_{2}$ can be thought as the preferred good of party $D$ and $g_{1}$ as the preferred good of part $R$. The rest of the model has the same setup and uses the same notation as the one presented in Section 1 in the main text.

A generic group $x$ in the state is populated by a mass one of identical agents with preferences over budget outcomes given by the utility function:

$$
w_{(x)}=\widetilde{y}-\tau+\alpha_{(x)} H\left(g_{1}\right)+\left(1-\alpha_{(x)}\right) H\left(g_{2}\right)
$$

where $\alpha_{(x)}=x \in[0,1]$ is the preference parameter described above, and $H(\cdot)$ is a continuous, twice differentiable, increasing, strictly concave function, implying decreasing marginal net benefits of spending programs. The lump sum tax $\tau$ and the group net endowment $\widetilde{y}=y+H(\bar{g})-\tau^{g}$, have the same interpretation as in the main paper. Recall that $\bar{g}$ is a general per capita spending, $H(\bar{g})-\tau^{g}>0$ is the net per capita benefit and $\tau^{g}=\bar{g}$ is the level of taxation that funds these general items. We assume $\tau^{g}=\bar{g}$ to be exogenously given. Within the model, the levels of $g_{1}$ and $g_{2}$ are an addition to this fixed level, and explain marginal changes in total spending due to the budgetary separation of powers.

The budget process has the same structure as in Section 1. The legislative majority proposes the tax level and the spending allocation. The governor can veto the budget. The budget must be balanced both at the proposal stage and after the veto: $g=g_{1}+g_{2}=$ $\tau$.

As in Section 1 in the main text, let $L$ denote the set of groups that support the legislative majority and $G$ denote the set of groups that support the governor. The majority party in the legislature chooses spending levels $\left(g_{1}, g_{2}\right)$ and overall taxation $\tau$, by solving the following maximization problem:

$$
\max _{g_{1}, g_{2}, \tau} W=\int_{x \in L} w_{(x)} d x, \text { subject to } g_{1}+g_{2} \leq \tau
$$


Under the line-item veto, the governor may only cut or trim spending chosen by the legislative majority and therefore solves the following maximization problem:

$$
\max _{g_{1}, g_{2}, \tau} W=\int_{x \in G} w_{(x)} d x, \text { subject to } g_{1}+g_{2} \leq \tau \text { and } g_{k} \leq g_{k L},
$$

where $g_{k L}$ denotes the level of type $k=1,2$ spending approved by the legislative majority. Note that (6) is equivalent to maximizing the welfare of the mean/median group in $B$.

Under the block veto, the governor chooses between the budget proposed by the legislative majority and a government shut-down, i.e., $\tau=g_{1}=g_{2}=\tau^{g}=\bar{g}=0$.

The timing of the game is as follows: 1) the exogenous election outcome determines the government configuration, which is fully observed by all players; 2) the legislature approves the budget bill and its implied tax level by simple majority; 3) the governor may veto the budget or cut programs according to the type of veto power available, line-item or block veto.

\section{A.3.1 Results and Intuition}

Without loss of generality, as in Section 1, consider the case in which the governor is from party $D$, with $s_{G} \in[0.5,1]$ given. We present the results in a parallel structure to those in the main paper.

Let $\bar{\alpha}_{B}^{P}$ denote the position of the median group in the segment $B \in\{L, G\}$ and party $P \in\{D, R\}$, as well as the weight given to good $g_{1}$ by the median group; $1-\bar{\alpha}_{B}^{P}$ is the weight given to $g_{2}$.

Lemma A.1 According to (5) and (6), the relative preference for $g_{1}$, for a branch (governorship of legislature) controlled by party $D$, is characterized by $\bar{\alpha}_{B}^{D}=\frac{s_{B}}{2} \leq \frac{1}{2}$. When party $R$ controls a branch, the relative preference for $g_{1}$ is characterized by $\bar{\alpha}_{B}^{R}=$ $1-\frac{s_{B}}{2} \geq \frac{1}{2}$.

See the proof in Section A.3.1. The position of the median group within each branch is the key to understanding the intuition of this version of the model. For a $D$ governor, the median group is at the point $\frac{s_{G}}{2}$ on the ideological line and it is located in the interval $[0,0.5]$. Under a unified government the median group for a legislative majority of party $D$ is located at $\frac{s_{L}}{2}$ and is also located in the interval $[0,0.5]$. Under a divided government, the median group of the legislative majority of party $R$ is at the point $1-\frac{s_{L}}{2}$, which is located in the interval $[0.5,1]$. Note that $s_{G} \geq 0.5$ and $s_{L} \geq 0.5$.

Lemma A.2 For $\frac{1}{2}<s_{G}<1$, the difference in preferences between the governor and 
the legislative majority is a continuous (and smooth function) of $s_{L}$ within a government configuration, but displays a discontinuity as the government configuration switches from a divided to a unified government.

See the proof in Section A.3.1. Let us focus on the legislative majority for the intuition. From lemma A.1, we can see that $\bar{\alpha}_{L}^{D}$ and $\bar{\alpha}_{L}^{R}$ are continuous functions in $s_{L}$, the size of the majority. Under a unified government the weight $\bar{\alpha}_{L}^{D}$ is increasing in $s_{L}$. As the size of the majority increases; the median group in $L$ moves to the right, giving more weight to $g_{1}$ and less to $g_{2}$. Under a divided government, as $s_{L}$ increases $\bar{\alpha}_{L}^{R}$ moves to the left, giving less weight to $g_{1}$ and more to $g_{2}$.

Under a unified government, if $s_{L}=\frac{1}{2}$, the relevant median group in $L$ is $\bar{\alpha}_{L}^{D}=\frac{1}{4}$. Under a divided government, if $s_{L}=\frac{1}{2}$, the relevant median group in $L$ is $\bar{\alpha}_{L}^{R}=\frac{3}{4}$. Thus, the divergence in preferences between branches jumps discontinuously:

$$
\bar{\alpha}_{G}^{D}-\bar{\alpha}_{L}^{P}\left(\frac{1}{2}\right)=\left\{\begin{array}{l}
\frac{s_{G}}{2}-\frac{1}{4}>0 \text { under unified, and } \\
\frac{s_{G}}{2}-\frac{3}{4}<0 \text { under divided government. }
\end{array}\right.
$$

We may now introduce Proposition A.1.

Proposition A.1 If the governor has line-item veto, for any given $\frac{1}{2} \leq s_{G}<1$, (a) taxes are discontinuous at $s_{L}=0.5$; (b) strictly increasing in the interval $s_{L} \in\left[\frac{1}{2}, s_{G}\right)$; (c) strictly decreasing in the interval $s_{L} \in\left[s_{G}, 1\right]$; (d) strictly decreasing in the interval $1-s_{L} \in\left(1-s_{G}, \frac{1}{2}\right) ;(e)$ and is also strictly decreasing in the interval $1-s_{L} \in\left[0,1-s_{G}\right]$.

See the proof in Section A.3.1.

Following the intuition presented in the main paper, the party that controls the agenda in the legislature proposes $g_{k L}=g_{k}\left(s_{L}\right)$, which we use to denote the legislative majority's preferred level for each item. It is weakly dominant for the legislative majority to propose their preferred level regardless of governor's expected actions. ${ }^{35}$ Any eventual subsequent cut does not affect the marginal cost of taxation (constant and equal to one) nor the marginal benefit of the other good, which depends exclusively on its own level. If the legislative majority proposes their preferred levels, $g_{1 L}\left(s_{L}\right)$ and $g_{2 L}\left(s_{L}\right)$, then the governor trims the excess over her own preferred level. By doing so, the governor increases the average welfare of her constituency linearly with the corresponding reduction in taxes according to (4). But the governor is not able to raise spending in case $g_{k L}<g_{k}\left(s_{G}\right)$ for type $k=1,2$, i.e., in the case the governor has a preferred level of $g_{k}$ that is higher than the preferred level of the legislative majority.

\footnotetext{
${ }^{35}$ There are other equilibria in which the legislative majority foresees the cut and proposes accordingly. All equilibria are outcome equivalent.
} 
We start at the last stage with the governor's decision. According to Lemma A.1, the Governor's preferred level of spending for each type of good is given by $g_{1 G}\left(s_{G}\right)=$ $H_{g}^{-1}\left(\frac{s_{G}}{2}\right)$ and $g_{2 G}\left(s_{G}\right)=H_{g}^{-1}\left(1-\frac{s_{G}}{2}\right)$. With line item veto power, the governor trims down legislative proposals $g_{k L}$ that are higher than the governor's preferred level $g_{k G}\left(s_{G}\right)$, $k=1,2$.

The legislative majority assigns zero resources to spending levels above her preferred level. The desired (maximum) expenditure proposed by $L$ is given by:

$g_{1 L}\left(s_{L}\right)=H_{g}^{-1}\left(\frac{2}{s_{L}}\right)$ and $g_{2 L}\left(s_{L}\right)=H_{g}^{-1}\left(\frac{2}{2-s_{L}}\right)$, under a unified government, and $g_{1 L}\left(s_{L}\right)=H_{g}^{-1}\left(\frac{2}{2-s_{L}}\right)$ and $g_{2 L}\left(s_{L}\right)=H_{g}^{-1}\left(\frac{2}{s_{L}}\right)$, under a divided government.

The legislative majority proposes up to her preferred level of spending to avoid any costly excess in taxation (this is a weakly dominant strategy and the equilibrium that obtains is outcome equivalent to all other equilibria). If the proposed level is above the governor's desired level of spending, the governor trims the level down to $g_{k}\left(s_{G}\right)$ for $k=1,2$. The equilibrium spending outcome with its corresponding tax level is given by:

$$
g\left(s_{L} ; s_{G}\right)=\tau\left(s_{L} ; s_{G}\right)=\min \left[g_{L}, g_{G}\right]
$$

with $g_{B}=g_{1 B}\left(s_{B}\right)+g_{2 B}\left(s_{B}\right)$ for $B=L, G$.

Part $(a)$. In Lemma A.2 it can be seen that the preference parameter changes discontinuously near the cutoff. The governor's preferences are closer to the majority's preferences under a unified government than under a divided government. This implies that at $s_{L}=0.5$, as the government switches from unified to divided, there is a discontinuous drop in the tax level.

The intuition is as follows. Under a divided government the governor prefers $g_{2}$ to $g_{1}$, but the legislative majority prefers $g_{1}$ to $g_{2}$. The governor trims $g_{1}$ heavily in equilibrium and the legislative majority proposes a low value for $g_{2}$; both $g_{1}$ and $g_{2}$ have low levels in equilibrium. Under a unified government both the governor and the legislative majority prefer $g_{2}$ to $g_{1}$. The legislative majority proposes high values for $g_{2}$ and low values for $g_{1}$ that are not heavily trimmed; $g_{1}$ has a low level, but $g_{2}$ has a high level. This implies that taxes are higher under a unified government.

More formally, note that at $s_{L}=0.5$ and under a divided government, the median group in $L$ is $\bar{\alpha}_{L}^{D}=\frac{3}{4}$, which implies that $g_{1 L}\left(s_{L}\right)=H_{g}^{-1}\left(\frac{4}{3}\right)$. Under a unified government at $s_{L}=0.5$, the median group in $L$ is $\bar{\alpha}_{L}^{D}=\frac{1}{4}$, which implies that $g_{1 L}\left(s_{L}\right)=H_{g}^{-1}(4) .{ }^{36}$

\footnotetext{
${ }^{36}$ Note that $\left(4, \frac{4}{3}\right)$ are simply the inverse of $\left(\frac{1}{4}, \frac{3}{4}\right)$. In general, $\left(\frac{2}{s_{B}}, \frac{2}{2-s_{B}}\right)$ are the inverse of $\left(\frac{s_{B}}{2}, 1-\frac{s_{B}}{2}\right)$.
} 
Since the governor is from party $D$ the median group in $G$ is $\frac{s_{G}}{2}, s_{G}>\frac{1}{2}$. This implies that the median group in $G$ is closer to the median group in $L$ in the case in which the government is unified (except for the extreme case $s_{G}=1$ ). The governor's preferences are given by $g_{1 G}\left(s_{G}\right)=H_{g}^{-1}\left(\frac{2}{s_{G}}\right)$. The conflict over preferred levels of spending is more acute under a divided government, since $\frac{s_{G}}{2}-\frac{1}{4}<\frac{3}{4}-\frac{s_{G}}{2}$ for any party $D$ governor with $s_{G}<1 .{ }^{37}$ Thus, total spending will be

$\lim _{s_{L} \rightarrow \frac{1}{2}^{+}} g\left(s_{L} ; s_{G}\right)=\lim _{s_{L} \rightarrow \frac{1}{2}^{+}} \min \left[g_{L}, g_{G}\right]=H_{g}^{-1}(4)+H_{g}^{-1}\left(\frac{2}{2-s_{G}}\right)$, under a unified government, and $\lim _{s_{L} \rightarrow \frac{1}{2}^{+}} g\left(s_{L} ; s_{G}\right)=\lim _{s_{L} \rightarrow \frac{1}{2}^{+}} \min \left[g_{L}, g_{G}\right]=H_{g}^{-1}\left(\frac{2}{s_{G}}\right)+H_{g}^{-1}(4)$, under a divided government.

with $\Delta g\left(\frac{1}{2} ; s_{G}\right)=\Delta \tau\left(\frac{1}{2}{ }_{L} ; s_{G}\right)=H_{g}^{-1}\left(\frac{2}{2-s_{G}}\right)-H_{g}^{-1}\left(\frac{2}{s_{G}}\right)>0$ for any $\frac{1}{2} \leq s_{G}<1$.

Part $(b)$. In this interval, equilibrium taxation under a unified government is given by:

$$
\tau\left(s_{L} ; s_{G}\right)=g_{A}\left(s_{L} ; s_{G}\right)=g_{1}\left(s_{L}\right)+g_{2}\left(s_{G}\right),
$$

since $g_{1}\left(s_{L}\right)<g_{1}\left(s_{G}\right)$ and $g_{2}\left(s_{G}\right)<g_{2}\left(s_{L}\right)$. Given $s_{G}>s_{L}$, the governor prefers higher(lower) levels of $g_{1}\left(g_{2}\right)$ than the legislative majority in this interval. The governor is therefore willing to cut any proposal with $g_{2 L}>g_{2}\left(s_{G}\right)$, thus the level of $g_{2}$ is fixed throughout this interval at $g_{2}=g_{2}\left(s_{G}\right)$. The governor, however, is willing to accept more spending in $g_{1}$. As $s_{L}$ increases, the legislative majority changes its preferences towards more $g_{1}$ and so the tax level rises.

Part $(c)$. For $s_{L} \geq s_{G}$, using the same intuition, equation (7) now switches to

$$
\tau\left(s_{L} ; s_{G}\right)=g_{A}\left(s_{L} ; s_{G}\right)=g_{1}\left(s_{G}\right)+g_{2}\left(s_{L}\right) .
$$

The governor is willing to cut any proposal with $g_{1 L}>g_{1}\left(s_{G}\right)$, thus the level of $g_{1}$ is fixed throughout this interval. The governor is willing to accept more spending in $g_{2}$, but the legislative majority is not willing to provide it. As $s_{L}$ increases, the legislative majority changes its preferences towards less $g_{2}$ (more $g_{1}$ ). As the level of $g_{1}$ is fixed, the tax level decreases as $s_{L}$ increases and the legislative majority proposes lower levels of $g_{2}$.

Part $(d)$ and $(e)$. Under a divided government, the legislative majority, with support in the interval $\left[1-s_{L}, 1\right]$, prefers $g_{1}$ to $g_{2}$. The median group in $L$ is $\bar{\alpha}_{L}^{R}=1-\frac{s_{L}}{2}$. The governor from party $D$ prefers $g_{2}$ to $g_{1}$ instead and trims down any proposal by the legislative majority that is higher than the governor's preferred level. In this interval

\footnotetext{
${ }^{37}$ Note that the legislative majority preferred level of total spending near the cutoff is the same, as the weights are $(1 / 4,3 / 4)$ for $D$, and $(3 / 4,1 / 4)$ for $R$.
} 
the level of $g_{1}$ is fixed throughout at the governor's preferred level: $g_{1}\left(s_{G}\right)=H_{g}^{-1}\left(\frac{2}{s_{G}}\right)$. The level of $g_{2}$ is determined by the median group in $L$ and it is lower than the level preferred by the governor throughout this interval. Therefore as $s_{L}$ increases to the left, the legislative majority of party $R$ prefers more and more $g_{2}$, which the governor does not veto. As $s_{L}$ increases, the tax level increases. Note that part $(e)$ has a different result than Proposition 1 in the main text, where the shape is ambiguous. In this version of the model there is no ambiguity as the the behavior of the tax level in the interval described in part (e) is identical to the behavior of the tax level described in part (d).

In summary, the tax level increases as $s_{L}$ increases away from the cutoff $s_{L}=0.5$, whether the government is unified or divided. Under a unified government the tax level increases until $s_{L}=s_{G}$ and decreases thereafter. Under an divided government the tax level increases until $s_{L}=1$. Taxes jump up at the cutoff $s_{L}=0.5$ as the government moves from divided to unified.

Proposition 2 If the governor has block veto, for any $\frac{1}{2} \leq s_{G}<1$ only the legislative majority determines both the set of beneficiaries and the level of transfers, and taxes are continuous at $s_{L}=\frac{1}{2}$.

With the block veto, all the action is driven by $s_{L}$. To see this, first note that it is too costly for the governor to exercise a block veto. The legislative majority assigns zero resources to spending levels above her preferred level. The desired (maximum) expenditure proposed by $L$ is given by:

$g_{L}^{*}=g_{1 L}\left(s_{L}\right)+g_{2 L}\left(s_{L}\right)=H_{g}^{-1}\left(\frac{2}{s_{L}}\right)+H_{g}^{-1}\left(\frac{2}{2-s_{L}}\right)$, under a unified government, and $g_{L}^{*}=g_{1 L}\left(s_{L}\right)+g_{2 L}\left(s_{L}\right)=H_{g}^{-1}\left(\frac{2}{2-s_{L}}\right)+H_{g}^{-1}\left(\frac{2}{s_{L}}\right)$, under a divided government.

As $s_{L}$ approaches $\frac{1}{2}$ from either side, the total level of spending is the same, although its composition varies. If party $D$ controls the legislature, spending in $g_{2}$ is higher than than spending in $g_{1}$; the reverse holds if $R$ controls the legislature. Arbitrarily close to the cutoff, the relevant weights for $g_{1}$ and $g_{2}$ switch from $\left(\frac{3}{4}, \frac{1}{4}\right)$ to $\left(\frac{1}{4}, \frac{3}{4}\right)$ as the government configuration changes from a divided to a unified configuration.

The shape of total taxation and spending is again ambiguous and depends on the specific functional form for $H(\cdot)$. In Proposition A1, we showed that the preferred level of spending for party $D$ majority in the legislature is

$$
g_{L}=g_{1}\left(s_{L}\right)+g_{2}\left(s_{L}\right)=H_{g}^{-1}\left(\frac{2}{s_{L}}\right)+H_{g}^{-1}\left(\frac{2}{2-s_{L}}\right) .
$$


Then the behaviour of taxes and spending under block veto is capture by

$$
\frac{\partial g_{L}}{\partial s_{L}}=-H_{g g}^{-1}\left(\frac{2}{s_{L}}\right) \times \frac{2}{s_{L}^{2}}+H_{g g}^{-1}\left(\frac{2}{2-s_{L}}\right) \times \frac{2}{\left(2-s_{L}\right)^{2}} \gtreqless 0 .
$$

Therefore, we can not predict whether the relationship between the tax level and $s_{L}$ is increasing or decreasing in states with the block veto, unless we impose additional assumptions on $H(\cdot)$. The robust features is that there is no jump in the tax level at the cutoff $s_{L}=0.5$.

\section{A.3.2 Proofs}

Proof (Lemma A.1 and Lemma A.2.) The strict quasiconcave program and the increasing utility imply an interior solution, with first order conditions as sufficient. We can solve the problem by simple substitution. When party $D$ controls $B \in\{L, G\}$, equation (5) can be rewritten as:

$$
\max _{g_{1}, g_{2}}\left\{s_{B}\left(y-g_{1}-g_{2}\right)+H\left(g_{1}\right) \int_{i \in B} \alpha_{(x)} d x+H\left(g_{2}\right)\left(s_{B}-\int_{x \in B} \alpha_{(x)} d x\right)\right\},
$$

where $\int_{x \in B} \alpha_{(x)} d x=\int_{0}^{s_{B}} x d x=\left.\frac{x^{2}}{2}\right|_{0} ^{s_{B}}=\frac{s_{B}^{2}}{2}$, and since $\int_{0}^{s_{B}} a d x=a s_{B}$. Thus the problem is equivalent to,

$$
\max _{g_{1}, g_{2}}\left\{s_{B}\left[\left(y-g_{1}-g_{2}\right)+\bar{\alpha}_{B} H\left(g_{1}\right)+\left(1-\bar{\alpha}_{B}\right) H\left(g_{2}\right)\right]\right\}
$$

with $\bar{\alpha}_{B}=\frac{s_{B}}{2}$ and $1-\bar{\alpha}_{B}=\frac{2-s_{B}}{2}$.

When party $R$ controls $B \in\{L, G\}$, the problem can be expressed as:

$$
\max _{g_{1}, g_{2}}\left\{s_{B}\left(y-g_{1}-g_{2}\right)+H\left(g_{1}\right) \int_{x \in B} \alpha_{(x)} d x+H\left(g_{2}\right)\left(s_{B}-\int_{x \in B} \alpha_{(x)} d x\right)\right\},
$$

where $\int_{x \in B} \alpha_{(x)} d x=\int_{1-s_{B}}^{1} x d x=\left.\frac{x^{2}}{2}\right|_{1-s_{B}} ^{1}=\frac{1-\left(1-s_{B}\right)^{2}}{2}=\frac{2 s_{B}-s_{B}^{2}}{2}=\frac{s_{B}\left(2-s_{B}\right)}{2}$ and since $\int_{1-s_{B}}^{1} a d x=a s_{B}, \forall a \in \mathbb{R}$. Thus the problem can be expressed as:

$$
\max _{g_{1}, g_{2}}\left\{s_{B}\left[\left(y-g_{1}-g_{2}\right)+\frac{2-s_{B}}{2} H\left(g_{1}\right)+\frac{s_{B}}{2} H\left(g_{2}\right)\right]\right\}
$$

Proof (Proposition 1.) From Lemma 1, the preferred level of expenditure and taxation for $B \in\{L, G\}$, controlled by party $D$, is given by:

$$
g_{B}=g_{1}\left(s_{B}\right)+g_{2}\left(s_{B}\right)=H_{g}^{-1}\left(\frac{2}{s_{B}}\right)+H_{g}^{-1}\left(\frac{2}{2-s_{B}}\right) .
$$


with $\frac{\partial g_{1}}{\partial s_{B}}>0$ and $\frac{\partial g_{2}}{\partial s_{B}}<0$.

Under a unified government, equilibrium spending is $g=\min \left[g_{L}, g_{G}\right]$. In the $\left(0.5, s_{G}\right)$, this implies that equilibrium taxation under a unified government $\tau^{\text {unif }}$ as a function of $s_{L}$ and given $s_{G}$ is:

$$
\tau^{\text {unif }}\left(s_{L} ; s_{G}\right)=g^{\text {unif }}\left(s_{L} ; s_{G}\right)=g_{1}\left(s_{L}\right)+g_{2}\left(s_{G}\right)
$$

since $g_{1}\left(s_{L}\right)<g_{1}\left(s_{G}\right)$ and $g_{2}\left(s_{G}\right)<g_{2}\left(s_{L}\right)$ for $s_{L}<s_{G}$. Thus $\frac{\partial g_{A}}{\partial s_{L}}=\frac{\partial g_{1}\left(s_{L}\right)}{\partial s_{L}}>0$. Therefore, $\tau$ increases just to the right of $\frac{1}{2}$.

Under a divided government, the preferred level for the majority in the legislature reverts weights:

$$
g_{L}=g_{1}\left(s_{L}\right)+g_{2}\left(s_{L}\right)=H_{g}^{-1}\left(\frac{2}{2-s_{L}}\right)+H_{g}^{-1}\left(\frac{2}{s_{L}}\right)
$$

Remember that now the groups in $\left[1-s_{L}, 1\right]$ are part of the majority and $1-s_{L}<\frac{1}{2}$ is the size of the minority in the legislature. For good one, $g_{1}\left(s_{G}\right)<g_{1}\left(s_{L}\right)=H_{g}^{-1}\left(\frac{2}{2-s_{L}}\right)$ and the governor trims it down $H_{g}^{-1}\left(\frac{2}{s_{G}}\right)$. This behaviour holds for any $s_{L}$ under divided configuration. Thus, under a divided configuration $g_{1}^{d i v}=H_{g}^{-1}\left(\frac{2}{s_{G}}\right)$ and has a flat shape in $s_{L}$. For good two, $g_{2}\left(s_{L}\right)<g_{2}\left(s_{G}\right)$ so that the size is set by $s_{L}$. Total spending is then given by:

$$
g^{d i v}=g_{1}\left(s_{G}\right)+g_{2}\left(s_{L}\right)=H_{g}^{-1}\left(\frac{2}{s_{G}}\right)+H_{g}^{-1}\left(\frac{2}{s_{L}}\right) .
$$

Then $\frac{\partial g^{d i v}}{\partial s_{L}}=\frac{\partial g_{2}}{\partial s_{L}}=-H_{g g}(\cdot) \frac{2}{s_{B}^{2}}>0$. To interpret the result correctly, note that when party $R$ weakens, approaching the cutoff point $\frac{1}{2}, s_{L}$-the size of the majority-decreases. Therefore, total spending decreases.

Tax and spending feature a v-shaped with both increasing as the size of the legislative majoriy increases, departing from $\frac{1}{2}$ in both directions.

To evaluate the behaviour at the cutoff (the v-vertex), consider the level of spending and taxation as $s_{L}$ gets sufficiently close to $\frac{1}{2}$ under both configuration. Then as the government moves from a divided to a unified configuration, the resulting fiscal effect is:

$$
\begin{aligned}
\Delta \tau & =g^{\text {align }}\left(\frac{1}{2} ; s_{G}\right)-g^{\operatorname{div}}\left(\frac{1}{2} ; s_{G}\right) \\
& =\left[H_{g}^{-1}(4)+H_{g}^{-1}\left(\frac{2}{2-s_{G}}\right)\right]-\left[H_{g}^{-1}\left(\frac{2}{s_{G}}\right)+H_{g}^{-1}(4)\right] \\
& =H_{g}^{-1}\left(\frac{2}{2-s_{G}}\right)-H_{g}^{-1}\left(\frac{2}{s_{G}}\right)>0 .
\end{aligned}
$$




\section{A.4 Robustness checks of the power series estimator}

Table 6: Choosing the polynomial degree for the partially linear estimator

\begin{tabular}{|c|c|c|}
\hline & \multicolumn{2}{|c|}{ Dependent Variable: state taxes over state GDP (\%) } \\
\hline \multirow[t]{2}{*}{ constant } & 6.79 & 6.95 \\
\hline & $(0.81)^{* * *}$ & $(0.67)^{* * *}$ \\
\hline \multirow{2}{*}{ Gov. strength $\times(1-$ right $)$} & 15.81 & 10.6 \\
\hline & $(5.24)^{* * *}$ & $(10.5)$ \\
\hline \multirow[t]{2}{*}{ Gov. strength ${ }^{2} \times(1-$ right $)$} & -138.78 & -72.0 \\
\hline & $(45.14)^{* * *}$ & $(125.6)$ \\
\hline \multirow[t]{2}{*}{ Gov. strength ${ }^{3} \times(1-$ right $)$} & 409.39 & 89.6 \\
\hline & $(134.39) * * *$ & $(599.5)$ \\
\hline \multirow[t]{2}{*}{ Gov. strength ${ }^{4} \times(1-$ right $)$} & -388.36 & 264.8 \\
\hline & $(128.40)^{* * *}$ & $(1247)$ \\
\hline \multirow[t]{2}{*}{ Gov. strength ${ }^{5} \times(1-$ right $)$} & - & -481.1 \\
\hline & - & $(944.3)$ \\
\hline \multirow[t]{2}{*}{ right $(1$ if Gov. strength $>50)$} & 2.58 & 1.85 \\
\hline & $(1.14)^{* *}$ & $(5.6)$ \\
\hline \multirow{2}{*}{ Gov. strength $\times($ right $)$} & -6.82 & -3.99 \\
\hline & $(3.12)^{* *}$ & $(24.2)$ \\
\hline \multirow[t]{2}{*}{ Gov. strength ${ }^{2} \times($ right $)$} & 5.09 & 1.17 \\
\hline & $(2.20)^{* *}$ & $(33.3)$ \\
\hline \multirow[t]{2}{*}{ Gov. strength ${ }^{3} \times($ right $)$} & - & 1.75 \\
\hline & - & $(14.9)$ \\
\hline Discontinuity & 0.33 & 0.35 \\
\hline at Gov. strenth $=50$ & $(0.16)^{* *}$ & $(0.20)^{*}$ \\
\hline Controls & $\begin{array}{l}\text { State and Year Dummies } \\
\text { and additional controls }\end{array}$ & $\begin{array}{l}\text { State and Year Dummies } \\
\text { and additional controls }\end{array}$ \\
\hline R-squared & 0.84 & 0.84 \\
\hline
\end{tabular}

Note: This sample comprises 1524 state-years from 1960 to 2006 with the line-item veto and an override requirement of two-thirds. The dependent variable is the total sum of a state's income, sales, and corporate taxes divided by state GDP and shown as a percentage. The explanatory variable, Gov. strength, is the minimum between the percentage of seats in the state House of Representatives and in the state Senate that belong to the same party as the governor. The variable right takes value 1 if Gov. strength $>0.5$ and zero otherwise. Standard errors in parenthesis are clustered by state (34 groups). The symbol $*$ means that the estimated coefficient is significant at $10 \% ; * *$ significant at $5 \% ; * * *$ significant at $1 \%$. The control variables are the same as those specified in the main text. 


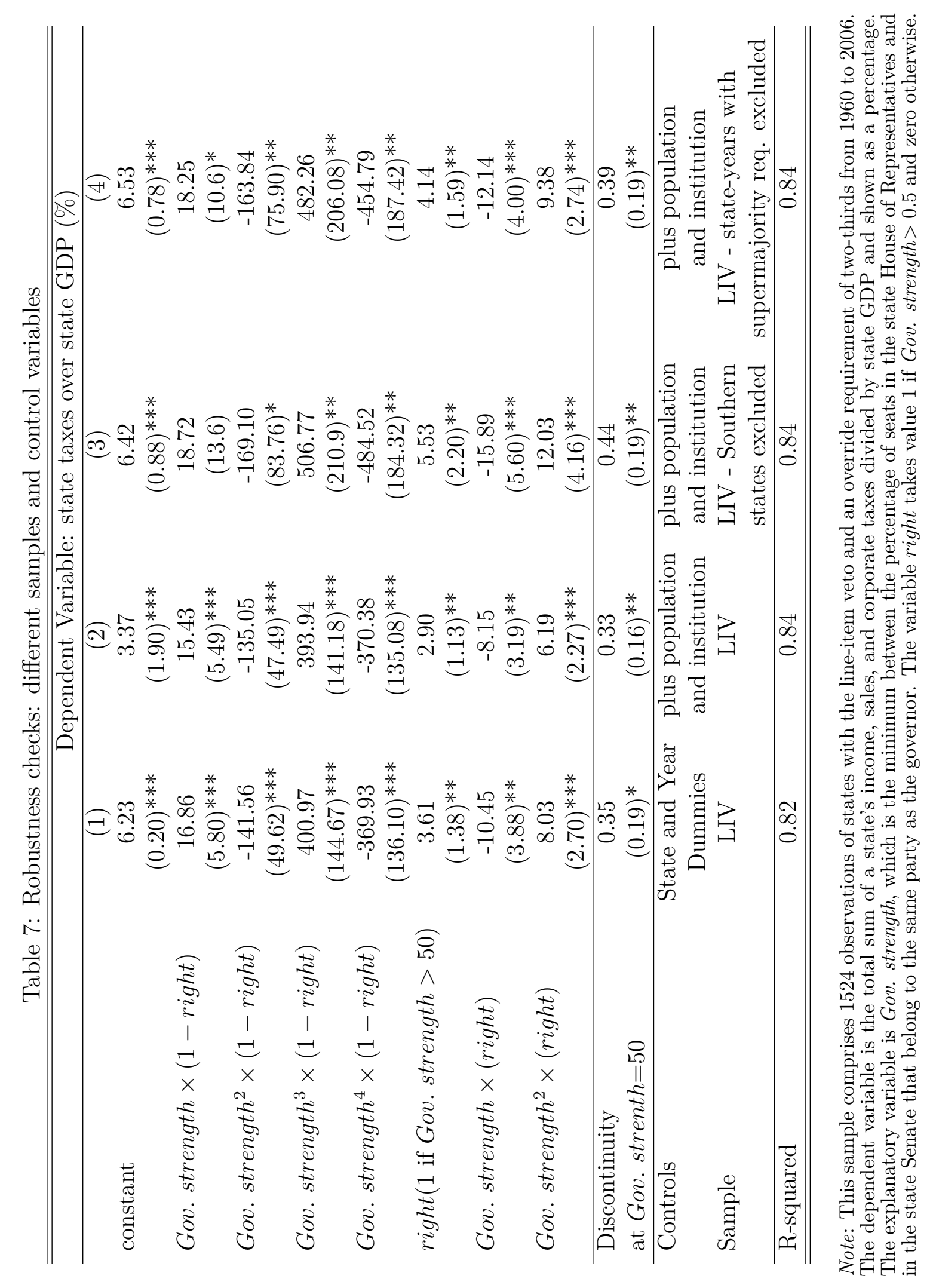


Table 8: Alternative Dependent Variables

\begin{tabular}{|c|c|c|}
\hline & 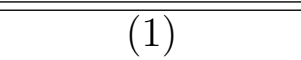 & 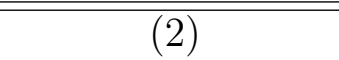 \\
\hline Dependent var. & taxes per capita & expenditure/GDP \\
\hline \multirow[t]{2}{*}{ constant } & 122 & 16.13 \\
\hline & $(113)$ & $(1.83)^{* * *}$ \\
\hline \multirow[t]{2}{*}{ Gov. strength $\times(1-$ right $)$} & 1892 & 30.15 \\
\hline & $(625)^{* * *}$ & $(18.18)$ \\
\hline \multirow[t]{2}{*}{ Gov. strength ${ }^{2} \times(1-$ right $)$} & -16996 & -273.56 \\
\hline & $(5410)^{* * *}$ & $(150.60)^{*}$ \\
\hline \multirow[t]{2}{*}{ Gov. strength ${ }^{3} \times(1-$ right $)$} & 51294 & 801.05 \\
\hline & $(16118)^{* * *}$ & $(424.19)^{*}$ \\
\hline \multirow[t]{2}{*}{ Gov. strength ${ }^{4} \times(1-$ right $)$} & -49454 & -747.79 \\
\hline & $(15424)^{* * *}$ & $(389.63)^{*}$ \\
\hline \multirow[t]{2}{*}{ right $(1$ if Gov. strength $>50)$} & 156 & 5.79 \\
\hline & $(154)$ & $(2.64)^{* *}$ \\
\hline \multirow[t]{2}{*}{ Gov. strength $\times($ right $)$} & -339 & -15.75 \\
\hline & $(439)$ & $(7.4)^{* *}$ \\
\hline \multirow[t]{2}{*}{ Gov. strength ${ }^{2} \times($ right $)$} & 254 & 10.82 \\
\hline & $(310)$ & $(5.19)^{* *}$ \\
\hline Discontinuity & 31.73 & 0.50 \\
\hline at Gov. strenth $=50$ & $(18.68)^{*}$ & $(0.32)$ \\
\hline R-squared & 0.93 & 0.99 \\
\hline
\end{tabular}

Note: The sample in column (1) comprises 1524 observations of states with the line-item veto and an override requirement of two-thirds from 1960 to 2006 . The sample in column (2) comprises 1553 observations of states with the line-item veto and an override requirement of two-thirds from 1960 to 1998. The dependent variable in column (1) is the total sum of a state's income, sales, and corporate taxes per capita in 1981 dollars. The dependent variable in column (2) is the total state expenditure divided by state GDP. Standard errors in parenthesis are clustered by state (34 groups). The symbol $*$ means that the estimated coefficient is significant at $10 \% ; * *$ significant at $5 \% ; * * *$ significant at $1 \%$. The control variables in the above regression are: state and year dummies, state population, state income per capita, an indicator variable for whether the state has a supermajority requirement for a tax increase in that year, an indicator variables for whether the state has a binding expenditure limitations in that year, an indicator variable for whether the election was midterm, an indicator variable for the party identity of the governor, and turnout in the last election. 


\section{A.5 Estimation of the partially linear model}

We estimate the model following the method described by Robinson (1988). ${ }^{38}$ To discuss estimation, let's rewrite the model as

$$
y=\beta^{\prime} x+f(g)+\epsilon
$$

The identifying assumption is that $E(\epsilon \mid x, g)=0$. In order to estimate $\beta$ note that:

$$
E(y \mid g)=\beta^{\prime} E(x \mid g)
$$

and by differencing the two equations above we have:

$$
y-E(y \mid g)=\beta^{\prime}(x-E(x \mid g))+\epsilon \text {. }
$$

The first step in the procedure is to estimate $\beta$. In order to so we need estimates for $E(y \mid g)$ and $E(x \mid g)$. We follow Schmalensee and Stoker (1999) and use a kernel estimator. We use the local linear procedure with a triangular kernel and the optimal bandwidth suggested by Imbens and Kalyararaman (2009).

The difference in our estimation method to previous estimations of a partially linear model is that we allow for a discontinuity in $E(y \mid g)$. We impose a cutoff at Governor's strength $=50$. In practice we impose a different bandwidth to data near the cutoff. To give an example, our bandwidth of choice $h=15^{39}$ implies that the estimation of $\hat{y_{30}}$ at the point $g=30$ includes observations in the interval $g \in[15,45]$. For the estimation of $\hat{y_{-}}$at $g=50$ the bandwidth only includes observations in the interval $g \in[35,50]$. For the estimation of $\hat{y_{+}}$at $g=50$ the bandwidth only includes observations in the interval $g \in(50,65]$.

Let the estimate of $E(y \mid g)$ be denoted $\hat{m}_{y}(g)$ and that of $E(x \mid g)$ be denoted $\hat{m}_{x}(g)$. Our estimate of $\beta$ come from the OLS of $y_{i}-\hat{m}_{y}\left(g_{i}\right)$ on $x_{i}-\hat{m}_{x}\left(g_{i}\right)$.

The last step of the procedure is to estimate the function $f(g)$ by running another local-linear regression of $y_{i}-\hat{\beta}^{\prime} x_{i}$ on $g_{i}$. We allow the estimate of $f(g)$ to be discontinuous at Governor's strength $=50$.

\footnotetext{
${ }^{38}$ The non-parametric part of the model can not be separately identified from a constant in X. So we do not include a constant in $\mathrm{X}$ and we must also drop one state dummy and one year dummy.

${ }^{39}$ Our choice of bandwidth comes from Imbens and Kalyararaman (2009) who propose a method to calculate an optimal bandwidth in a non-parametric setting specifically for when the function is allowed to be discontinuous. Their method yields a bandwidth of 15 when applied to the tax level and Governor's strength.
} 


\section{A.6 Alternative definition of Governor's strength}

Table 9: Dependent Variable: taxes_GDP - Explanatory Variable: Gov. strength_max

\begin{tabular}{|c|c|c|}
\hline constant & $\begin{array}{l}4.98 \\
(1.83)^{* *}\end{array}$ & $\begin{array}{l}5.65 \\
(2.96)^{* *}\end{array}$ \\
\hline Gov. strength_max $\times(1-$ right $)$ & $\begin{array}{l}36.94 \\
(22.67)\end{array}$ & $\begin{array}{l}21.7 \\
(61.1)\end{array}$ \\
\hline Gov. strength_max ${ }^{2} \times(1-$ right $)$ & $\begin{array}{l}-193.54 \\
(125.85)\end{array}$ & $\begin{array}{l}-75.0 \\
(487.2)\end{array}$ \\
\hline Gov. strength_max ${ }^{3} \times(1-$ right $)$ & $\begin{array}{l}407.50 \\
(292.86)\end{array}$ & $\begin{array}{l}-20.5 \\
(1799)\end{array}$ \\
\hline Gov. strength_max ${ }^{4} \times(1-$ right $)$ & $\begin{array}{l}-296.83 \\
(240.58)\end{array}$ & $\begin{array}{l}432.0 \\
(3115)\end{array}$ \\
\hline Gov. strength_max ${ }^{5} \times(1-$ right $)$ & - & $\begin{array}{c}-472.8 \\
(2048)\end{array}$ \\
\hline right(1 if Gov. strength_max $>50)$ & $\begin{array}{l}4.19 \\
(1.58)^{* *}\end{array}$ & $\begin{array}{l}-1.03 \\
(5.3)\end{array}$ \\
\hline Gov. strength_max $\times($ right $)$ & $\begin{array}{l}-5.22 \\
(2.28) * *\end{array}$ & $\begin{array}{l}13.9 \\
(23.5)\end{array}$ \\
\hline Gov. strength ${ }^{2} \_\max \times($ right $)$ & $\begin{array}{l}3.75 \\
(1.76)^{* *}\end{array}$ & $\begin{array}{l}-22.6 \\
(32.4)\end{array}$ \\
\hline Gov. strength ${ }^{3} \_\max \times($ right $)$ & - & $\begin{array}{l}11.9 \\
(14.5)\end{array}$ \\
\hline $\begin{array}{l}\text { Discontinuity } \\
\text { at Gov. strenth_max }=50\end{array}$ & $\begin{array}{l}0.05 \\
(0.12)\end{array}$ & $\begin{array}{l}-0.00 \\
(0.14)\end{array}$ \\
\hline Controls & $\begin{array}{l}\text { State and Year Dummies } \\
\text { and additional controls }\end{array}$ & $\begin{array}{l}\text { State and Year Dummies } \\
\text { and additional controls }\end{array}$ \\
\hline R-squared & 0.84 & 0.84 \\
\hline
\end{tabular}

Note: This sample comprises 1524 observations of states with the line-item veto and an override requirement of two-thirds from 1960 to 2006. The dependent variable is the total sum of a state's income, sales, and corporate taxes divided by state GDP and shown as a percentage. The explanatory variable is Gov. strength_max, which is the maximum between the percentage of seats in the state House of Representatives and in the state Senate that belong to the same party as the governor. The variable right takes value 1 if Gov. strength_max $>0.5$ and zero otherwise. 
Table 10: State tax level and Governor's strength_max

\begin{tabular}{|c|c|c|}
\hline Method & Jump at $50 \%$ & $\overline{\mathrm{SE}}$ \\
\hline Polynomial: 4-degree and 3-degree & 0.10 & $(0.31)$ \\
\hline Polynomial: 3-degree and 3-degree & -0.06 & $(0.27)$ \\
\hline Polynomial: 4-degree and 4-degree & -0.25 & $(0.33)$ \\
\hline
\end{tabular}

Note: This sample comprises 1524 observations of states with the line-item veto and an override requirement of two-thirds from 1960 to 2006. Each observation represents a state within a year. The dependent variable is the total sum of a state's income, sales, and corporate taxes divided by state GDP and shown as a percentage. The explanatory variable is Gov. strength_max, which is the maximum between the percentage of seats in the state House of Representatives and in the state Senate that belong to the same party as the governor. The discontinuity is estimated at Gov. strength_max $=50 \%$. Row 1 shows the result for a 4-degree polynomial on the left side of the cutoff and a 3-degree polynomial on the right side; row 2 shows the results for a 3-degree polynomial on each side of the cutoff; row 3 for a 4-degree polynomial on each side. Cluster (by state) robust standard errors are provided in parenthesis.

\section{A.7 Regression Discontinuity Design - robustness checks}

Table 11: Tax level and Governor's strength in the House: one decade excluded at a time (4-degree polynomial)

\begin{tabular}{lcc}
\hline \hline Excluded decade & Jump at 50\% & SE \\
\hline $1960 \mathrm{~s}$ & 0.69 & $(0.33)^{* *}$ \\
$1970 \mathrm{~s}$ & 0.71 & $(0.39)^{*}$ \\
$1980 \mathrm{~s}$ & 0.79 & $(0.39)^{*}$ \\
$1990 \mathrm{~s}$ & 0.69 & $(0.40)^{*}$ \\
$2000 \mathrm{~s}$ & 0.64 & $(0.37)^{*}$ \\
\hline
\end{tabular}

Note: This sample comprises state-years with the line-item veto from 1960 to 2006 . We exclude one decade at a time. Each regression is run with 1369, 1342, 1342, 1346, and 1449 observations, respectively. The dependent variable is the percentage of the sum of income, sales, and corporate taxes in a state divided by state GDP and shown as a percentage. The forcing variable is Governor's strength in the House, the percentage of seats in the state House of Representatives that belong to the same party as the governor. The discontinuity is estimated at Governor's strength in the House $=50 \%$. Each row shows the results for a 4-degree polynomial on each side of the cutoff. Theoretical cluster-robust standard errors by state are in parentheses. 
Table 12: Tax level and Governor's strength in the House: one state excluded at a time (4-degree polynomial)

\begin{tabular}{lcllcl}
\hline \hline Excluded & Jump at 50\% & Cluster robust-SE & Excluded & Jump at 50\% & SE \\
\hline AL & 0.70 & $(0.35)^{*}$ & AZ & 0.71 & $(0.35)^{*}$ \\
CO & 0.72 & $(0.36)^{*}$ & CT & 0.74 & $(0.36)^{* *}$ \\
DE & 0.73 & $(0.35)^{* *}$ & FL & 0.67 & $(0.35)^{*}$ \\
GA & 0.69 & $(0.35)^{*}$ & IA & 0.65 & $(0.35)^{*}$ \\
IL & 0.64 & $(0.38)^{*}$ & KS & 0.71 & $(0.36)^{*}$ \\
KY & 0.66 & $(0.36)^{*}$ & LA & 0.66 & $(0.36)^{*}$ \\
MA & 0.57 & $(0.33)^{*}$ & MD & 0.70 & $(0.35)^{*}$ \\
MI & 0.70 & $(0.38)^{*}$ & MO & 0.65 & $(0.35)^{*}$ \\
MS & 0.74 & $(0.35)^{* *}$ & MT & 0.68 & $(0.37)^{*}$ \\
ND & 0.72 & $(0.37)^{*}$ & NJ & 0.62 & $(0.35)^{*}$ \\
NM & 0.65 & $(0.35)^{*}$ & NY & 0.71 & $(0.36)^{*}$ \\
OH & 0.71 & $(0.35)^{*}$ & OK & 0.74 & $(0.35)^{* *}$ \\
OR & 0.68 & $(0.36)^{*}$ & PA & 0.97 & $(0.33)^{* * *}$ \\
SC & 0.71 & $(0.35)^{*}$ & SD & 0.71 & $(0.36)^{*}$ \\
TN & 0.72 & $(0.36)^{*}$ & TX & 0.62 & $(0.34)^{*}$ \\
UT & 0.69 & $(0.35)^{*}$ & VA & 0.66 & $(0.35)^{*}$ \\
WA & 0.71 & $(0.37)^{*}$ & WI & 0.55 & $(0.31)^{*}$ \\
WV & 0.66 & $(0.35)^{*}$ & WY & 0.64 & $(0.36)^{*}$ \\
\hline
\end{tabular}

Note: This sample comprises tate-years with line-item veto from 1960 to 2006 . Each regression is run with 1665 observations. The first exception is the regression excluding Connecticut, that has 1669 observations, as Connecticut had fours years with an independent governor dropped. The regressions excluding Iowa, Washington and West Virginia have 1674 observations each, as these states adopted the line-item veto in 1969 . The dependent variable is the percentage of the sum of income, sales, and corporate taxes in a state divided by state GDP and shown as a percentage. The forcing variable is Governor's strength in the House, the percentage of seats in the state House of Representatives that belong to the same party as the governor. The discontinuity is estimated at Governor's strength in the House $=50 \%$. In each entry, we exclude from the sample the state in columns 1 or 3 . Each row shows the results for a 4-degree polynomial on each side of the cutoff. Theoretical cluster-robust standard errors by state are in parentheses. 
Table 13: Tax level and Governor's strength in the House - alternative cutoff points (4-degree polynomial)

\begin{tabular}{lll}
\hline \hline Cutoff point(\%) & Jump & SE \\
\hline 45 & 0.29 & $(1.22)$ \\
46 & 0.36 & $(0.81)$ \\
47 & 0.27 & $(0.66)$ \\
48 & 0.00 & $(0.37)$ \\
49 & 0.35 & $(0.36)$ \\
50 & 0.69 & $(0.35)^{*}$ \\
51 & 0.35 & $(0.42)$ \\
52 & 0.36 & $(0.34)$ \\
53 & 0.27 & $(0.51)$ \\
54 & 0.34 & $(0.80)$ \\
55 & 0.66 & $(0.96)$ \\
\hline
\end{tabular}

Note: This sample comprises 1712 observations of states with the line-item veto from 1960 to 2006. Each observation represents a state within a year. The dependent variable is the percentage of the sum of income, sales, and corporate taxes in a state divided by state GDP and shown as a percentage. The forcing variable is Governor's strength in the House, the percentage of seats in the state House of Representatives that belong to the same party as the governor. The discontinuity is estimated at different cutoff values of Governor's strength in the House. Each row shows the results for a 4-degree polynomial on each side of the cutoff. Cluster-robust standard errors are in parentheses. 